\title{
Measurements to Determine the Regimes of Turbulent Premixed Flames
}

\author{
Aaron W. Skiba ${ }^{1}$, Timothy M. Wabel ${ }^{2}$, Jacob E. Temme ${ }^{3}$, and James F. Driscoll ${ }^{4}$ \\ Department of Aerospace Engineering \\ University of Michigan, Ann Arbor MI 48109
}

\begin{abstract}
Structural features of highly turbulent piloted flames were acquired from simultaneous PLIF images of formaldehyde $\left(\mathrm{CH}_{2} \mathrm{O}\right)$ and $\mathrm{OH}$. The lean (equivalence ratio $\left.=0.75\right)$ methane-air flames were studied under eight different flow conditions and at two different interrogation regions. The non-reacting conditions for these flames consist of turbulent Reynolds numbers $\left(\operatorname{Re}_{T}\right)$, turbulence intensities $\left(u^{\prime} / S_{L}\right)$, and integral length scales that range from 520 to 80,000, 5 to 184 , and $6 \mathrm{~mm}$ to $29 \mathrm{~mm}$, respectively. Preheat and reaction zone thicknesses were measured for flames subjected to these range of values. The preheat zone thickness was deduced from the $\mathrm{CH}_{2} \mathrm{O}$ PLIF images and the reaction zone thicknesses were obtained from the profiles produced by the pixel-by-pixel product of the $\mathrm{OH}$ and $\mathrm{CH}_{2} \mathrm{O}$ PLIF images. The reaction or preheat zones associated with a particular condition were classified as being "thickened" if the mean thickness for that condition exceeded two but not four times the laminar value. If the average thickness was greater than four times the laminar value that preheat or reaction zone was deemed "primarily distributed." Eight of the eleven cases possessed "primarily distributed" preheat zones, while the other three were "thickened." A reaction zone was further characterized as being "moderately distributed" if more than $20 \%$ but less than $40 \%$ of it was identified as being "locally distributed." A particular portion of a reaction zone is found to be "locally distributed" if that portion is both four times thicker than the laminar value and its length to thickness ratio is less than four. All of the reaction zones near the burner's exit were "thickened" and, except in one case, were also deemed "moderately distributed." Additionally, all of the reaction layers in the downstream interrogation region were "primarily distributed." Yet, regardless of being categorized as "moderately" or "primarily distributed," each case's reaction zones exhibited regions of both relatively thin and distributed reactions. In fact the appearance of the observed reaction zones can best be described as resembling "chicken noodle soup." That is, in any given instantaneous image relatively thin, "noodle-like" reaction layers are generally accompanied by thicker "chunky-chicken-like" reaction regions. Furthermore, the observed reaction zone structures in a particular case typically fail to correspond to those predicted by the turbulent premixed combustion regime diagram. This suggests that the regime diagram requires alterations if it is to properly forecast the appearance of a flame based on a simple set of operating conditions. The data set presented here is currently too limited to enable a thorough re-mapping of the regime diagram. However, based on their structural features, the cases considered here were classified into appropriate regimes of combustion.
\end{abstract}

\section{Introduction}

In comparison to non-premixed and rich, premixed flames, lean premixed flames are advantageous because they produce lower temperatures and consume nearly all of the fuel fed to them. Operating at lower temperatures reduces the amount of $\mathrm{NO}_{\mathrm{x}}$ production, while complete fuel consumption inhibits the production and subsequent emission of unburnt hydrocarbons (UHCs). Given the increasingly stringent emission policies, it is not surprising that modern power-production and propulsion systems have begun to implement lean, premixed combustion

\footnotetext{
${ }^{1}$ Research Assistant, Department of Aerospace Engineering, AIAA Member.

${ }^{2}$ Research Assistant, Department of Aerospace Engineering, AIAA Member.

${ }^{3}$ Post-Doctoral Research Fellow, Department of Aerospace Engineering, AIAA Member.

${ }^{4}$ Professor, Department of Aerospace Engineering, AIAA Fellow.
} 
strategies. Modern power-production and propulsion devices generally operate under highly turbulent conditions, which enhance mixing and allow the devices to be more compact.

Yet, the presence of highly turbulent flows within such devices renders their design and development quite challenging. Practical and economical design of these devices necessitates the implementation of computational models. The accuracy of turbulent premixed combustion models rests on their ability to properly simulate the underlying physics inherent to such combustion. However, the fundamental physics of premixed combustion occurring within the highly turbulent flows of modern, low-emission devices is currently unresolved. Thus, this work attempts to expand the combustion community's understanding of premixed flames to turbulent conditions exceeding those in previous studies.

Numerous studies ${ }^{1-18}$ of turbulent premixed flames have been conducted with large turbulence intensities (i.e. $u^{\prime} / S_{L}$, where $u^{\prime}$ is square root of the velocity's variance and $S_{L}$ is the un-stretched laminar flame speed) but with rather small integral length scales (typically on the order of several millimeters). Yet, modern combustion devices generally operate with both large turbulence intensities and integral length scales. That is, in realistic devices, combustion occurs within flows where both u' and $\lambda$ are large; or, in other words, when the turbulence Reynolds number $\left(\operatorname{Re}_{\mathrm{T}}\right)$ is large. Where,

$$
\operatorname{Re}_{\mathrm{T}}=\frac{\mathrm{u}^{\prime} \lambda}{v}
$$

and $v$ is the kinematic viscosity.

Besides $\mathrm{Re}_{\mathrm{T}}$, the turbulent Damköhler $\left(\mathrm{Da}_{\mathrm{T}}\right)$ and turbulent Karlovitz $\left(\mathrm{Ka}_{\mathrm{T}}\right)$ numbers are two additional dimensionless parameters used to characterize turbulent premixed combustion. The Damköhler number represents the ratio of time scales associated with large flow structures to those of a flame's chemical reactions. In contrast, the Karlovitz number signifies the ratio of a flame's chemistry time scale to those of the smallest structures in a turbulent flow. The turbulent Damköhler and turbulent Karlovitz numbers are defined as:

$$
\begin{gathered}
\mathrm{Da}_{\mathrm{T}}=\frac{\mathrm{S}_{\mathrm{L}}^{2} \lambda}{\mathrm{u}^{\prime} v} \\
\mathrm{Ka}_{\mathrm{T}}=\frac{\delta_{\mathrm{F}, \mathrm{L}} u^{\prime 3}}{\mathrm{~S}_{\mathrm{L}}^{3} \lambda}
\end{gathered}
$$

where $\delta_{\mathrm{F}, \mathrm{L}}$ is the un-stretched laminar flame thickness.

As $\mathrm{Ka}_{\mathrm{T}}$ increases and $\mathrm{Da}_{\mathrm{T}}$ decreases the characteristic time scales of turbulence become comparable to those of a flame's chemical reactions. In fact, it is theorized that once $\mathrm{Da}_{\mathrm{T}}$ drops below or $\mathrm{Ka}_{\mathrm{T}}$ rises above a critical value, the smallest scales of a turbulent flow not only penetrate a flame but contain enough energy to dramatically distort its spatial structure ${ }^{19,20}$. In fact, Williams ${ }^{19}$ suggests that a flame's chemical reactions become distributed (i.e. significantly smeared over a large spatial region) for conditions in which $\mathrm{Da}_{\mathrm{T}}<1$. In contrast, Peters ${ }^{20}$ postulates that premixed flames become broken when $\mathrm{Ka}_{\mathrm{T}}>100$. Yet, based on direct numerical simulations (DNSs), Aspden et al. $^{21}$ insisted that both broken and distributed reactions may be present when $\mathrm{Ka}_{\mathrm{T}}$ is sufficiently large. Furthermore, Zhou et al. ${ }^{18}$ point out that whether a flame exhibits broken or distributed reactions may rest on how well it is shielded by a hot coflow.

Prior to the work presented here, few experimental studies have been conducted in which turbulence levels were high enough to produce distributed or broken reaction zones. For instance, prior to 2009 flame structure imaging experiments typically operated with $\mathrm{Re}_{\mathrm{T}}$ values no greater than $2,000^{1-11}$. Nearly all of the reaction layers in these studies were rather thin and continuous. However, significant flame extinction was observed by Mansour et al. ${ }^{12}$, Chen et al. ${ }^{13}$, and Chen and Mouser ${ }^{14}$ in highly strained Bunsen flames that were surrounded by a large diameter pilot. Similar flames surrounded by a hot coflow were investigated by Dunn et al. ${ }^{15,16}$, who observed localized flame extinction when $\operatorname{Re}_{\mathrm{T}}$ was 3,700 and 5,500. 
More recently, Zhao et al. ${ }^{17,18}$ conducted flame structure measurements in a jet flame surrounded by a relatively large porous-plug pilot, where $\mathrm{Re}_{\mathrm{T}}$ was approximately 5,000. Though they did not report evidence of local flame extinction, planar laser induced florescence (PLIF) images of $\mathrm{CH}$ radicals did suggest the presence of distributed reactions. Regions of distributed combustion were also observed by Aspden et al. ${ }^{21}$. In their DNS studies of three-dimensional Hydrogen flames in a box, distributed reaction zones were found to exists when $\mathrm{Da}_{\mathrm{T}}=$ $1.52 \times 10^{-2}$ and $\mathrm{Ka}_{\mathrm{T}}=266$. This demonstrates that in addition to having large values of $\mathrm{Re}_{\mathrm{T}}$, having large $\mathrm{Ka}_{\mathrm{T}}$ and low $\mathrm{Da}_{\mathrm{T}}$ values may be required in order for flames to possess distributed reactions.

The "distributed reaction" region is one of several to appear on the turbulent premixed combustion regime diagram. There are currently two ways of plotting the turbulent premixed combustion regime diagram. The first is the regime diagram as proposed by $\mathrm{F}$. Williams ${ }^{19}$, which plots $\mathrm{Da}_{\mathrm{T}}$ as a function of $\mathrm{Re}_{\mathrm{T}}$ on a $\log$-log scale. The second is the diagram proposed by Peters ${ }^{20}$ and Borghi ${ }^{22}$, which adopts $\mathrm{u}^{\prime} / \mathrm{S}_{\mathrm{L}}$ and $\lambda / \delta_{\mathrm{F}, \mathrm{L}}$ as the governing parameters. The authors believe that both methods of plotting the regime diagram are adequate and that neither one is particularly better than the other. However, for brevities sake, this document only presents the diagram proposed by Borghi and Peters. This "Borghi Diagram" is provided in Figure 1.

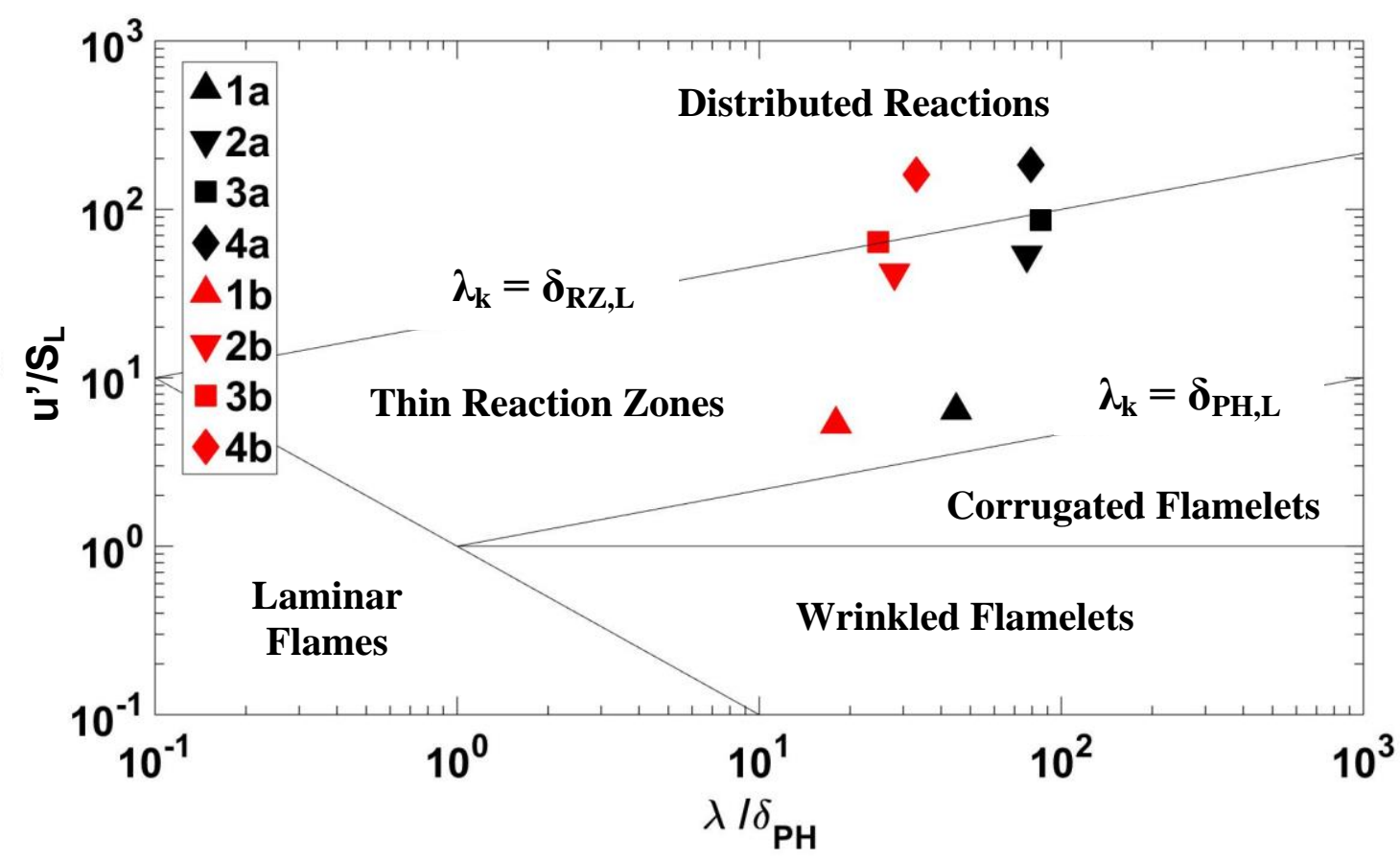

Figure 1. The turbulent premixed combustion regime diagram proposed by Borghi ${ }^{22}$, and Peters ${ }^{20}$, which has a modified $\mathrm{x}$-axis and includes the cases considered in this paper. Nomenclature: $\delta_{\mathrm{RZ}, \mathrm{L}}$ is the un-stretched laminar reaction zone thickness and $\lambda_{\mathrm{k}}$ is the Kolmogorov length scale.

Notice that the "Borghi Diagram" in Figure 1 contains two modifications: the present experimental test cases have been included and the $\mathrm{x}$-axis is normalized by the un-stretched laminar preheat zone thickness, $\delta_{\mathrm{PH}, \mathrm{L}}$ instead of $\delta_{\mathrm{F}, \mathrm{L}}$. To remain consistent with this modification, $\delta_{\mathrm{F}, \mathrm{L}}$ in the definition of $\mathrm{Ka}_{\mathrm{T}}$, is also replaced by $\delta_{\mathrm{PH}, \mathrm{L}}$; thus:

$$
\mathrm{Ka}_{\mathrm{T}}=\frac{\delta_{\mathrm{PH}, \mathrm{L}} u^{\prime 3}}{\mathrm{~S}_{\mathrm{L}}^{3} \lambda}
$$

The definition of $\delta_{\mathrm{PH}, \mathrm{L}}$ stems from the fact that the thickness of the total thermal front of an un-stretched laminar flame is the sum of the preheat and reaction zones; namely:

$$
\delta_{\mathrm{F}, \mathrm{L}}=\delta_{\mathrm{PH}, \mathrm{L}}+\delta_{\mathrm{RZ}, \mathrm{L}}
$$


Where $\delta_{\mathrm{RZ}, \mathrm{L}}$ is the un-stretched laminar reaction zone thickness. Thus $\delta_{\mathrm{PH}, \mathrm{L}}$ is the difference between $\delta_{\mathrm{F}, \mathrm{L}}$ and $\delta_{\mathrm{RZ}, \mathrm{L}}$. Similarly, the turbulent flame thickness is defined as:

$$
\delta_{\mathrm{F}, \mathrm{T}}=\delta_{\mathrm{PH}, \mathrm{T}}+\delta_{\mathrm{RZ}, \mathrm{T}}
$$

Measuring the quantities in Eq. (8) is one of the objectives of this work.

\section{Experimental configuration}

This section outlies the experimental setup and the diagnostics used to conduct the work presented in this paper.

\section{A. Burner design and diagnostics}

All of the flames investigated in this paper were produced by the Hi-Pilot Burner (HPB). A schematic of the HPB and an image of it operating are shown below in Figure 2.

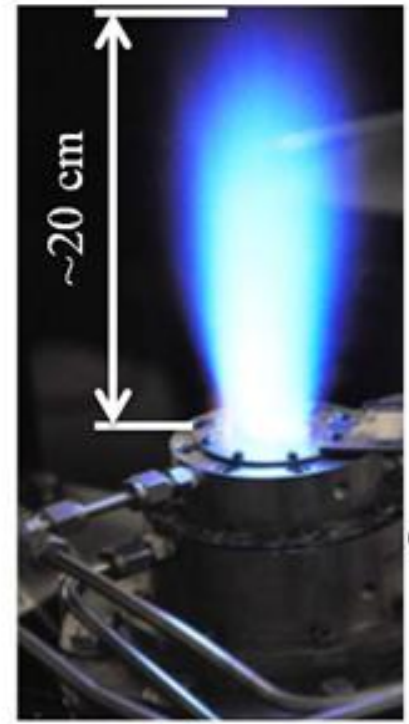

(a)

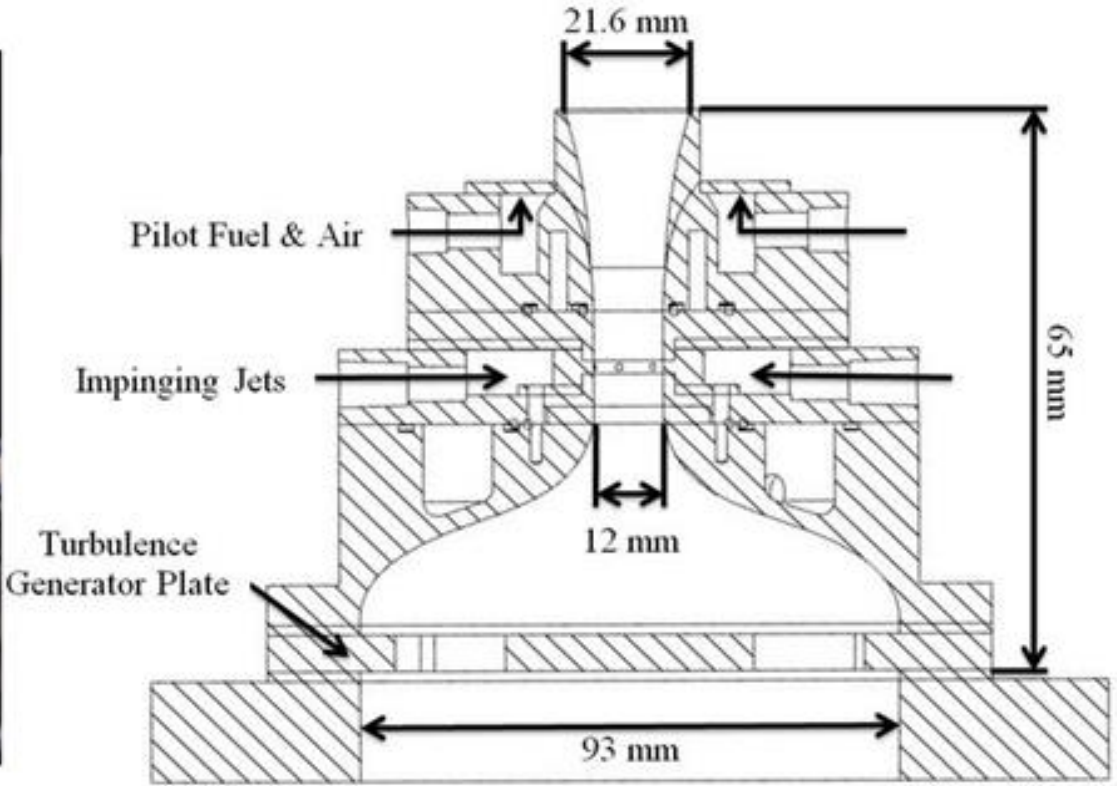

(b)

Figure 2. An image of the burner operating at $\operatorname{Re}_{\mathrm{T}}=22,000$ in (a) and a schematic of the Hi-Pilot burner in (b).

The HPB is designed to provide turbulence levels $\left(\mathrm{u}^{\prime} / \mathrm{S}_{\mathrm{L}}\right)$ and integral scales $(\lambda)$ that are nearly uniform in space, which avoids ambiguities as to where conditions lie on the regime diagram. This is achieved by expanding the flow at the jet exit, producing a relatively constant downstream turbulence level. Note that this approach avoids a problem inherent to experiments using a straight-sided jet, which exhibit a turbulence level that decays linearly with downstream distance. An additional benefit of expanding the flow at the jet exit is the prevention of flame flashback, as the diverging walls produce gas velocities that increase in the upstream direction.

The HPB utilizes a slotted-contraction device, similar to that of Marshall et al. ${ }^{23}$ and Videto and Santavicca ${ }^{24}$, to generate intense turbulence levels ( $\left.u^{\prime}\right)$. Premixed reactants impinge on a slotted plate placed upstream of a converging-diverging section; this plate is labeled as the Turbulence Generator Plate in Figure $2 \mathrm{~b}$. Two separate plates were utilized in these efforts; a diagram of these plates is provided in Figure 3. 


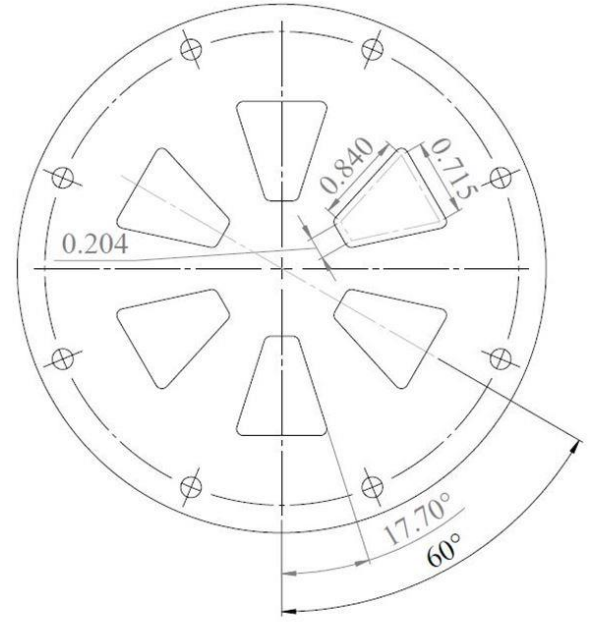

(a)

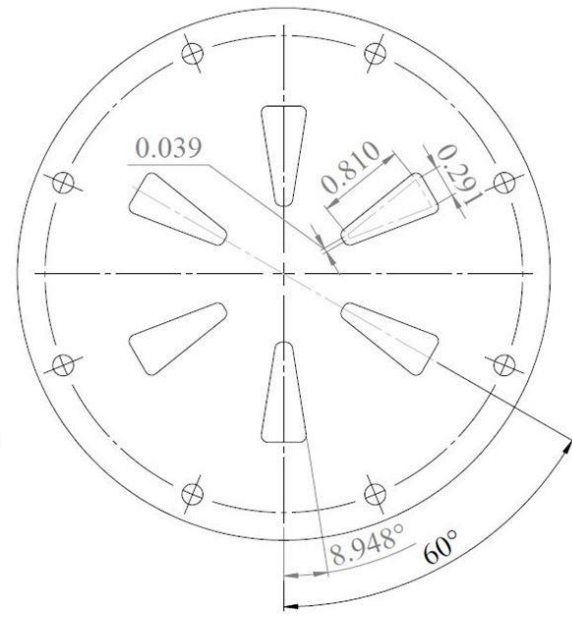

(b)

Figure 3. Slotted turbulence generating plates for the HPB. Note that the dimensions are given in inches.

These separate plates allow the HPB to generate two different flow conditions for a single flow rate. Four different flow rates on the two slotted plates were tested in this experiment, resulting in a total of 8 distinct operating conditions. The test cases were labeled $1-4 \mathrm{a}$ and $1-4 \mathrm{~b}$, with the increasing numbers representing increasing mass flow rate, and the letters representing either slotted plate ' $a$ ' or ' $b$ '. The larger slotted plate (shown in Figure 3a) generally produced larger values of $u$ ' and $\lambda$ than the smaller slotted plate (shown in Figure $3 b$ ).

The vertical structures that shed from these plates elongate through the HPB's contraction section and create very large turbulence intensities. The amount of turbulence is enhanced by the addition of impinging jets of the same equivalence ratio, injected perpendicular to the main flow at the throat of the converging-diverging section. This has the effect of breaking up the large eddies shed by the slotted plate, as well as adding turbulent energy to the flow. The impinging jets are operated at $6 \%$ of the main flow rate. Operating conditions for the HPB are listed in Table 1 below. Note that case 1 was operated without impinging jets (to reduce the turbulence).

\begin{tabular}{ccccccccc}
\hline Case & $\mathrm{U}_{0}(\mathrm{~m} / \mathrm{s})$ & $\mathrm{u}^{\prime}(\mathrm{m} / \mathrm{s})$ & $\lambda(\mathrm{mm})$ & $\mathrm{Re}_{\mathrm{T}}$ & $\mathrm{Da}_{\mathrm{T}}$ & $\mathrm{Ka}_{\mathrm{T}}$ & $\mathrm{u}^{\prime} / \mathrm{S}_{\mathrm{L}}$ & $\lambda / \delta_{\mathrm{PH}, \mathrm{L}}$ \\
\hline $1 \mathrm{a}$ & 6.2 & 1.5 & 16 & 1,600 & 38 & 2.5 & 6 & 45 \\
$1 \mathrm{~b}$ & 5.1 & 1.2 & 6 & 520 & 18 & 2.9 & 5 & 18 \\
$2 \mathrm{a}$ & 40 & 12 & 28 & 22,000 & 7.8 & 42 & 54 & 77 \\
$2 \mathrm{~b}$ & 30 & 10 & 10 & 6,400 & 3.7 & 54 & 42 & 28 \\
$3 \mathrm{a}$ & 55 & 20 & 31 & 40,000 & 5.4 & 86 & 86 & 85 \\
$3 \mathrm{~b}$ & 37 & 15 & 9 & 8,700 & 2.1 & 104 & 64 & 25 \\
$4 \mathrm{a}$ & 110 & 43 & 29 & 80,000 & 2.3 & 281 & 184 & 79 \\
$4 \mathrm{~b}$ & 79 & 37 & 12 & 29,000 & 1.1 & 349 & 161 & 33 \\
\hline
\end{tabular}

Table 1. Operating conditions for Methane - air combustion with an equivalence ratio of 0.75 and with a reactant temperature $\left(T_{1}\right)$ and pressure $\left(P_{1}\right)$ of $300 \mathrm{~K}$ and $1 \mathrm{~atm}$, respectively. Nomenclature: $\mathrm{U}_{0}$ is the centerline velocity measured approximately $5 \mathrm{~mm}$ above the burner, while $\mathrm{u}^{\prime}, \lambda, \mathrm{Re}_{\mathrm{T}}, \mathrm{Da}_{\mathrm{T}}, \mathrm{Ka}_{\mathrm{T}}, \mathrm{S}_{\mathrm{L}}$, and $\delta_{\mathrm{PH}, \mathrm{L}}$ are all defined in the text.

Additionally, a CHEMKIN simulation of a freely propagating flame with these specifications and using the GRIMech 3.0 mechanism gave $\mathrm{S}_{\mathrm{L}}=23.2 \mathrm{~cm} / \mathrm{s}$ and $\delta_{\mathrm{PH}, \mathrm{L}}=0.36 \mathrm{~mm}$.

The flow field was characterized using a Laser Doppler Velocimeter (LDV) system. An Argon-Ion laser operating at 1.5 Watts (Coherent Innova 90c) and a commercial Doppler burst correlator (TSI FSA 4000) were used to measure the axial component of the jet centerline velocity. The tracer species used in this experiment was $0.5 \mu \mathrm{m}$ alumina-oxide particles, while the optical components and photomultiplier tube consisted of standard commercial LDV equipment (TSI). The LDV focal volume was approximately $5 \mathrm{~mm}$ above the burner centerline. 
Simultaneous planar laser induced florescence (PLIF) images of the formaldehyde molecule $\left(\mathrm{CH}_{2} \mathrm{O}\right)$ and the Hydroxyl radical $(\mathrm{OH})$ were acquired by two Andor iStar intensified CCD cameras binned $(2 \times 2)$ to 512 x 512 pixels and firing at $2.5 \mathrm{~Hz}$. Formaldehyde $\left(\mathrm{CH}_{2} \mathrm{O}\right)$ was excited by the third harmonic of a Spectra-Physics Nd:YAG laser operating at $355 \mathrm{~nm}$ and approximately $135 \mathrm{~mJ} /$ pulse. The returning $\mathrm{CH}_{2} \mathrm{O}$ fluorescence was filtered using a high and low pass filter (CG385 and BG3, respectively) transmitting wavelengths between 385 and $490 \mathrm{~nm}$. The $\mathrm{OH}$ beam was excited using a second Spectra-Physics Nd:YAG laser pumping a Sirah dye laser. The dye was tuned to output $564.14 \mathrm{~nm}$, which was then doubled using a BBO crystal to $282.7 \mathrm{~nm}$ to excite the $\mathrm{Q}_{1}(3)$ transition of $\mathrm{OH}^{25}$. Typical laser power was $4.5 \mathrm{~mJ} /$ pulse at $282.7 \mathrm{~nm}$. The camera capturing $\mathrm{OH}$ fluorescence was equipped with a bandpass filter centered at $310+/-5 \mathrm{~nm}$. Gate times for both cameras were limited to $100 \mathrm{~ns}$ and the laser pulses were separated by $200 \mathrm{~ns}$ to avoid cross-talk ${ }^{26}$. A diagram depicting the simultaneous PLIF imaging setup is provided below in Figure 4. Note that for the sake of clarity only one set of sheet forming optics is shown; however, the $\mathrm{OH}$ and $\mathrm{CH}_{2} \mathrm{O}$ laser sheets were formed with two separate sets of sheet-forming optics, and were overlapped before being focused over the burner centerline.

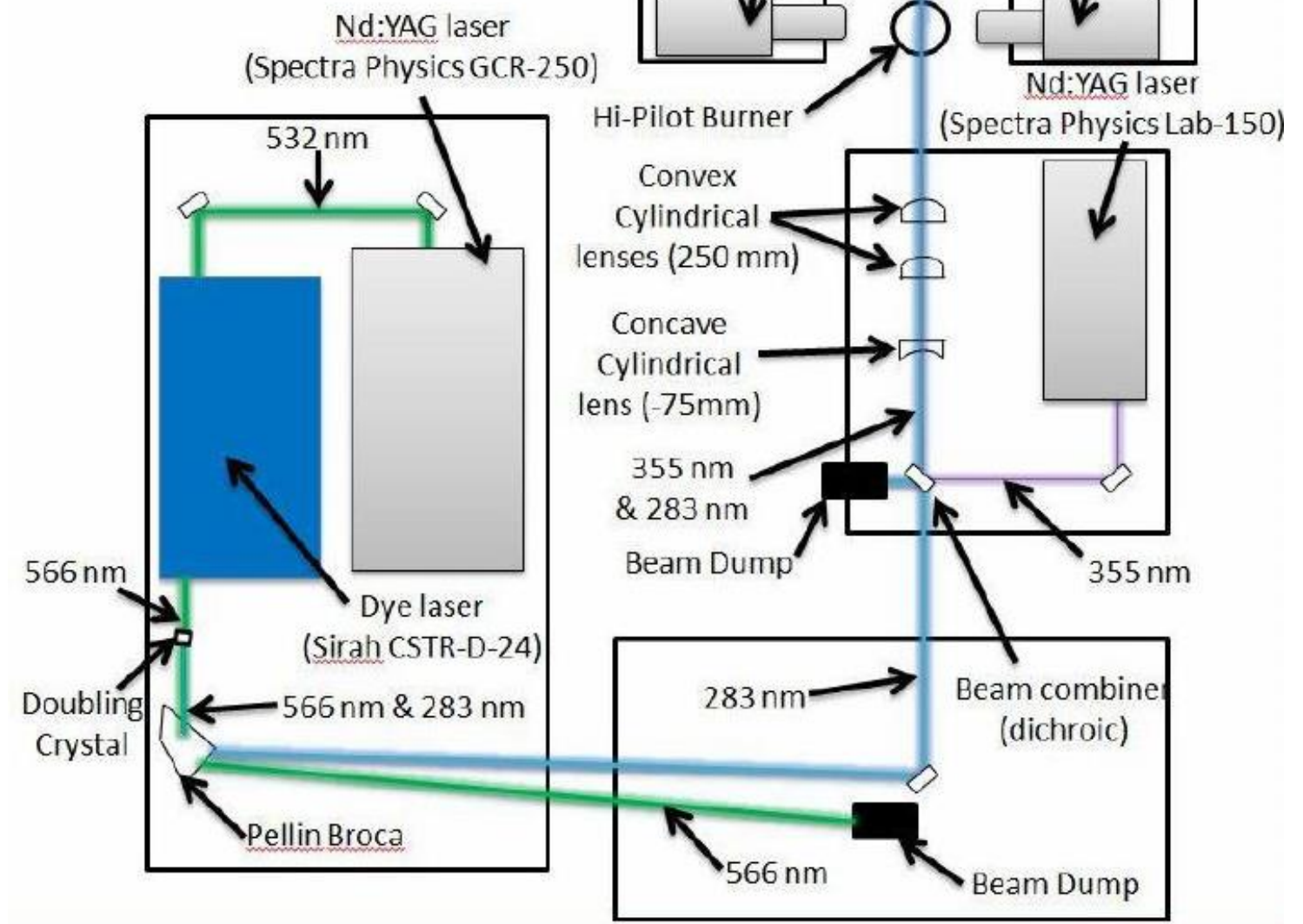

Figure 4. Schematic of the simultaneous $\mathrm{CH}_{2} \mathrm{O}-\mathrm{OH}$ PLIF system.

The reaction zone thickness is defined to be the width of the $\mathrm{CH}_{2} \mathrm{O}-\mathrm{OH}$ overlap layer at $50 \%$ of its maximum value (FWHM). Previous studies ${ }^{27-40}$ have also used the overlap of $\mathrm{OH}$ and $\mathrm{CH}_{2} \mathrm{O}$ or $\mathrm{HCO}$ to define the reaction layer. This is because the primary pathway for $\mathrm{HCO}$ production (and subsequently heat release) involves reactions with $\mathrm{CH}_{2} \mathrm{O}$ and $\mathrm{OH}$. Specifically, $\mathrm{OH}+\mathrm{CH}_{2} \mathrm{O} \Rightarrow \mathrm{HCO}+\mathrm{H}_{2} \mathrm{O}$, and thus the rate of production of $\mathrm{HCO}$ is proportional to $[\mathrm{OH}] \mathrm{x}[\mathrm{CH} 2 \mathrm{O}]$. Figure 5 shows CHEMKIN profiles calculated for a freely propagating laminar premixed methane-air flame (equivalence ratio $=0.75$ ). The thickness $\left(\delta_{\mathrm{RZ}, \mathrm{L}}\right)$ was found to be $0.18 \mathrm{~mm}$ in the CHEMKIN simulations of a premixed laminar flame, and was used to normalize the PLIF thickness measurements. 


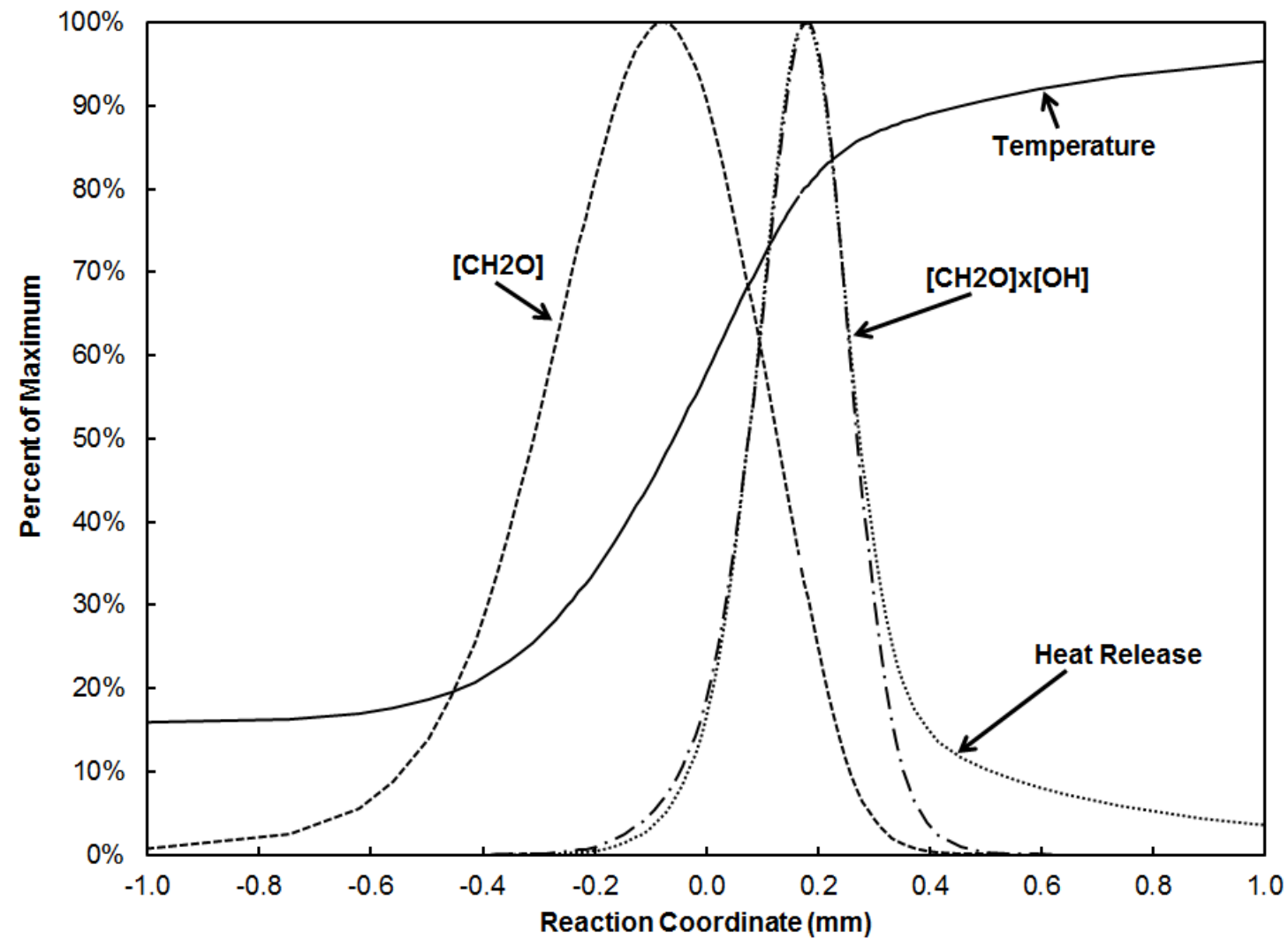

Figure 5. CHEMKIN laminar flame computations showing that $\mathrm{CH}_{2} \mathrm{O}$ marks the preheat zone while the $\mathrm{CH}_{2} \mathrm{O}-\mathrm{OH}$ overlap layer marks the reaction zone.

Li et al. ${ }^{41}$ showed that $\mathrm{CH}_{2} \mathrm{O}$ can also be used as a marker of the preheat zone. The preheat zone thickness is defined here as the width of the $\mathrm{CH}_{2} \mathrm{O}$ signal from its $35 \%$ point on the reactant side to the leading edge of the reaction zone (defined above as the half-maximum value on the reactant side). The leading edge of the flame was selected to be where $\mathrm{CH}_{2} \mathrm{O}$ signal is $35 \%$ of its maximum value because CHEMKIN shows that at this location the gas temperature is $550 \mathrm{~K}$. This temperature was selected to be the upstream boundary of the preheat zone. The unstretched, laminar value of the preheat zone thickness $\left(\delta_{\mathrm{PH}, \mathrm{L}}\right)$ computed by CHEMKIN was $0.36 \mathrm{~mm}$, which was used to normalize subsequent PLIF measurements.

\section{B. Image post processing}

Reaction zone thicknesses are identified as the full-width at half-maximum of the pixel-by-pixel product of the $\mathrm{OH}$ and $\mathrm{CH}_{2} \mathrm{O}$ images. Prior to the multiplication process several steps were taken to improve the quality of the raw images. First background noise was removed from the raw $\mathrm{OH}$ and $\mathrm{CH}_{2} \mathrm{O}$ images, which were then corrected for variations in laser sheet intensity. After this adjustment a combination of median and level-set filters ${ }^{42,43}$ were applied to remove salt and pepper noise. Following this filtering the $\mathrm{OH}$ images were transformed so that they would register to the $\mathrm{CH}_{2} \mathrm{O}$ images. The transform matrix was produced by imaging a double-sided grid target with both cameras. This target, which consisted of crosses printed on both sides of a thin transparent sheet, was placed in the cameras' field of view and was aligned with the laser sheets. Finally, the pixel-by-pixel multiplication of these modified images was performed. below.

An example of how the reaction zone is obtained from filtered $\mathrm{OH}$ and $\mathrm{CH}_{2} \mathrm{O}$ images is provided in Figure 6 

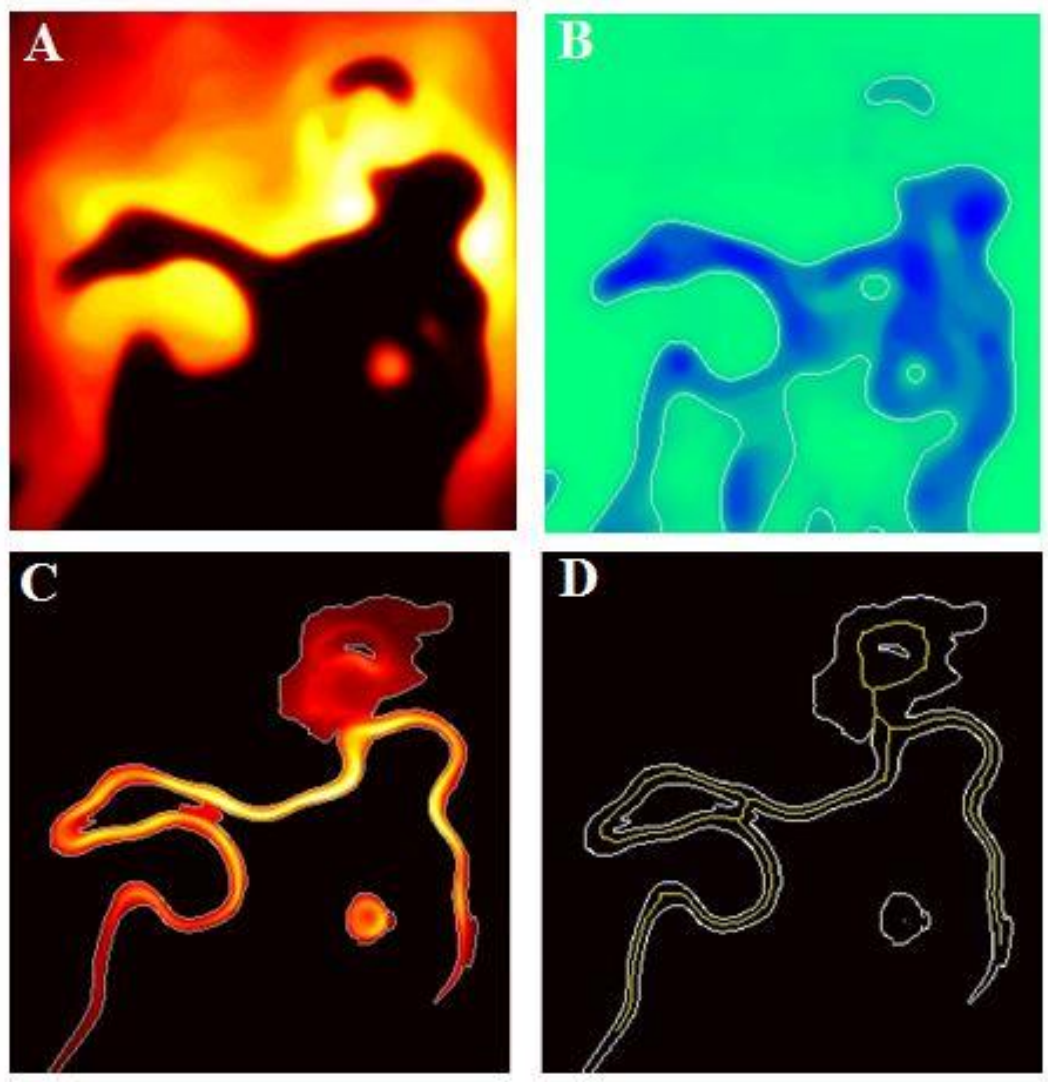

Figure 6. (A) and (B) display filtered, instantaneous PLIF image of $\mathrm{OH}$, and $\mathrm{CH}_{2} \mathrm{O}$, respectively. (C) exhibits the locally thresholded pixel-by-pixel product of the $\mathrm{OH}$ and $\mathrm{CH}_{2} \mathrm{O}$ images presented in (A) and (B). While (D) displays the edge (in white) and the skeleton (in yellow) associated with the reaction zone shown in (C).

Panel (c) of Figure 6 is a prime example of how the reaction zone can assume any arbitrary shape and orientation. Due to this vast variation in shape and orientation the full-width at half-maximum (FWHM) of the product images is obtained by implementing a local thresholding method.

The thresholding method first implements a global threshold that was generated based on the standard deviation of the signal. All pixels with an intensity count greater than twice the standard deviation of the image's intensity were set to one, while the rest were set to zero. A skeleton (such as the one depicted by the yellow line in Figure 6D) is then formed from this newly binarized image. This skeleton is used for local thresholding, since it represents a first guess at where the flame lies. Each pixel in the product image is compared to the nearest skeleton pixel; that is, each pixel is thresholded not relative to a field constant, but to the value of a point in the image where a flame is believed to be located. The thresholding process is repeated several times, using the previous result as the input to the next iteration, and typically converges to a solution in approximately three iterations. In this way, thresholding the image was done locally instead of globally, which helps to avoid errors introduced by naturally occurring variations in intensity of $\mathrm{CH}_{2} \mathrm{O}-\mathrm{OH}$ overlap in the field of view (FOV).

Once the product images were properly thresholded an average reaction and preheat zone thickness was calculated for each image as follows. First, the distance between each pixel on the skeleton and the nearest pixel on an edge of the reaction zone was determined. Then, these distances where multiplied by a factor of two to account for the fact that the skeleton lies along the center of the reaction zones. Finally, summing these distances over the whole skeleton in a particular image and subsequently dividing this summation by the length of that skeleton produced an average thickness value for that image. The average preheat zone thickness for a specific image was computed in a similar fashion; the only difference being that the $\mathrm{CH}_{2} \mathrm{O}$ signal was thresholded at $35 \%$ and then modified to exclude regions identified as reaction zone (i.e. the $\mathrm{CH}_{2} \mathrm{O}-\mathrm{OH}$ overlap layers were subtracted from the $\mathrm{CH}_{2} \mathrm{O}$ signal). 


\section{Results}

This section provides details about flow-field measurements and both qualitative and quantitative flame properties for each of the four cases described in Table 1 above.

\section{A. LDV Flow-field Characterization}

Turbulence level and integral scale measurements were made with the laser velocimeter system and the results are listed in Table 1. For each case in the test matrix, 4-6 LDV measurements consisting of 500,000 samples each were collected. Autocorrelations were computed using the normalized slotting method of Mayo et al. ${ }^{44,45}$. The resulting averaged autocorrelation functions for each case are shown in Figure 7.

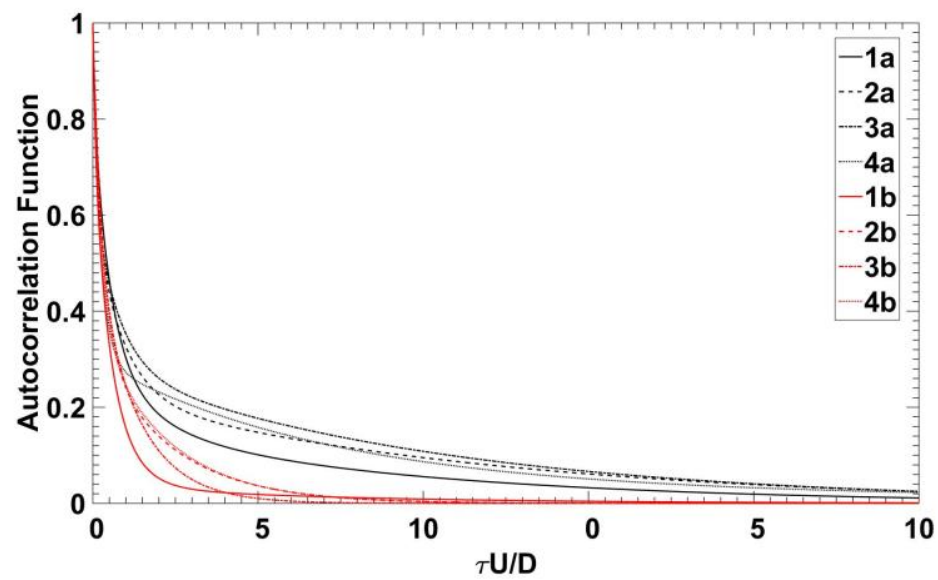

Figure 7. Autocorrelation function for the HPB's test cases.

The corresponding length scales, defined as the integral of the autocorrelation curve, are given in Table 1. Figure 7 demonstrates that by employing the separate turbulence generator plates, the HPB can produce a relatively large range of integral length scales. The integral length scales for cases $1 a-4 a$ and $1 b-4 b$ were found to range between 16 and $31 \mathrm{~mm}$ and 6 and $12 \mathrm{~mm}$, respectively.

Note that integral length scales cannot be directly obtained from LDV measurements. LDV data can provide integral time scales, however, which are commonly converted to a length scale using Taylor's "frozen turbulence" hypothesis. This simplification holds that in the case of very small turbulent fluctuations $\mathrm{u}^{\prime}<<\mathrm{U}_{0}$, the mean velocity provides a linear transformation between length and time scales. Thus, in the frozen flow regime,

$$
\lambda(\mathrm{x})=\tau(\mathrm{t}) * \mathrm{U}_{0}
$$

In Eq. (9), $\tau(t)$ is the integral of the autocorrelation, i.e. the area under the curve for each case in Figure 7. However, in the event of very large turbulent fluctuations, this linear approach is no longer valid. Flows issuing from the HPB have turbulence intensities exceeding $40 \%$ in some cases, and thus $\mathrm{u}^{\prime} \sim \mathrm{U}_{0}$ and a more general transformation is required. Following the approach of $\mathrm{Wu}$ and Patterson ${ }^{46,47}$, the relation between length scale and time scale for a flow with only a single component of mean velocity $\left(\mathrm{U}_{0}\right.$, the centerline velocity, with zero mean radial velocity) and isotropic turbulence $\left(\mathrm{u}_{1}{ }^{\prime}=\mathrm{u}_{2}{ }^{\prime}=\mathrm{u}_{3}{ }^{\prime}=\mathrm{u}^{\prime}\right)$ is:

$$
\lambda(\mathrm{x})=\tau(\mathrm{t}) * \mathrm{U}_{0} \sqrt{1+5 \frac{u^{\prime}}{\mathrm{U}_{0}}}
$$

This modification to the traditional method of converting LDV time scales to length scales avoids the simplification inherent with Taylor's hypothesis. The corresponding integral length scale measurements are given in Table 1.

\section{B. $\mathrm{CH}_{2} \mathrm{O}-\mathrm{OH} \mathrm{PLIF}$ results}

This section discusses patterns identified in instantaneous PLIF images of $\mathrm{CH}_{2} \mathrm{O}$ and $\mathrm{OH}$ as well as several measurements made from these images. 


\section{a. $\mathrm{OH}, \mathrm{CH}_{2} \mathrm{O}$, and $\mathrm{CH}_{2} \mathrm{O}-\mathrm{OH}$ overlap images}

To provide a holistic view of the flame, a single large field of view (22 mm x $36 \mathrm{~mm}$ ) PLIF image is displayed for cases $1 \mathrm{a}-4 \mathrm{a}$ in Figure 8 below. Note however that in general this FOV was not large enough to image the flame from base to tip.
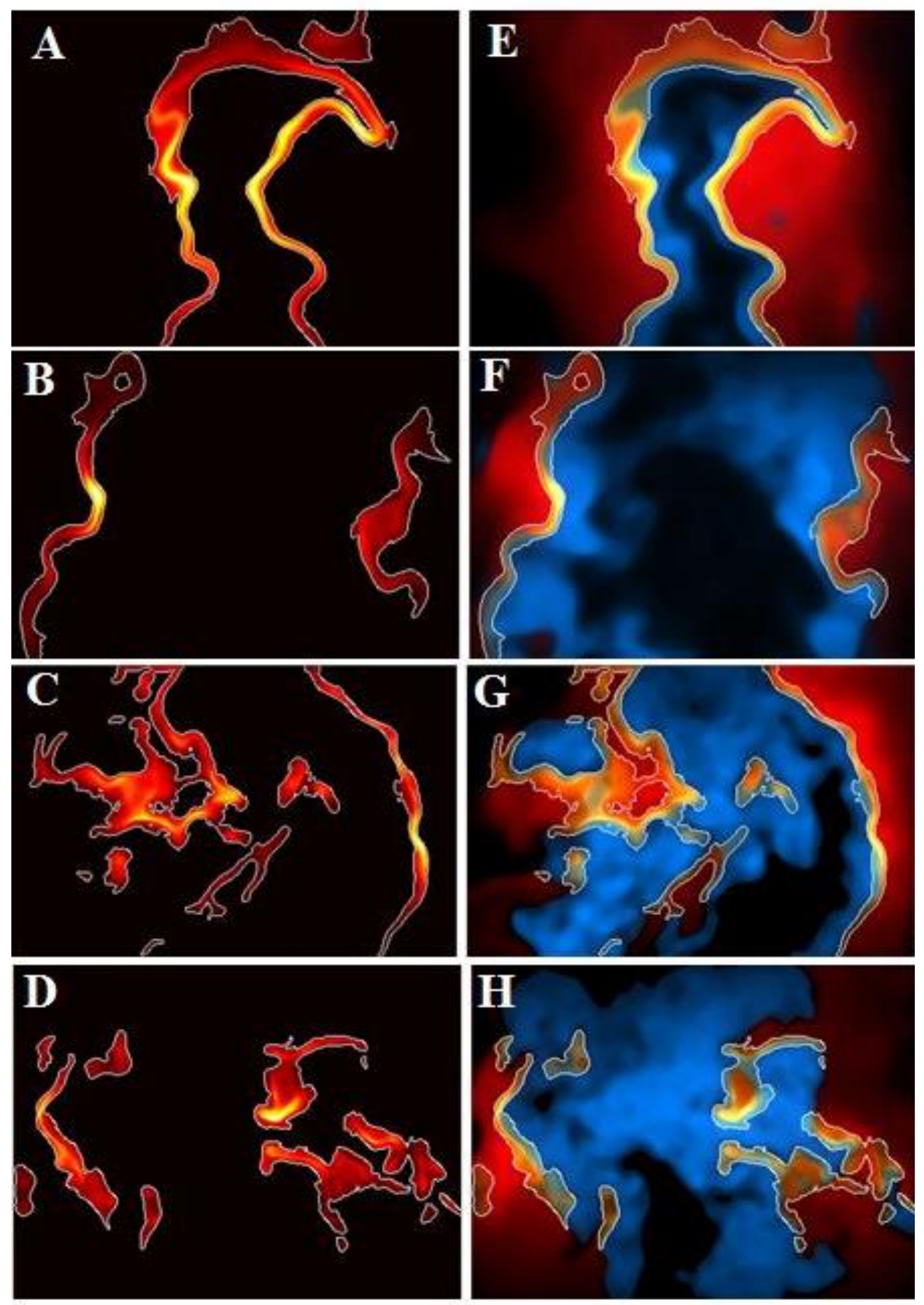

Figure 8. Panels (A) - (D) display post-processed, instantaneous reaction zones within a $22 \times 36 \mathrm{~mm}^{2}$ field of view for cases $1 \mathrm{a}-4 \mathrm{a}$, respectively. Panels $(\mathrm{E})-(\mathrm{H})$ show PLIF images of $\mathrm{CH} 2 \mathrm{O}$ (blue), $\mathrm{OH}$ (red), and reaction zone (yellow) for cases $1 \mathrm{a}-4 \mathrm{a}$, respectively. Note that the lower edge of each image is $5 \mathrm{~mm}$ above the burner and the centerline of each image is the burner's centerline. 
The blue regions (which represent $\mathrm{CH}_{2} \mathrm{O}$ signal) in the right panels of Figure 8 show that the preheat zone thickness tends to increase with increasing turbulence intensity. Additionally, Figure 8 also indicates that the preheat zone thickness increases with height above burner (HAB). This trend is particularly clear in panels (G) and (H) of Figure 8. Here, for heights greater than $20 \mathrm{~mm}$ above the burner, $\mathrm{CH}_{2} \mathrm{O}$ is found throughout the entire central region of the flame. Similar results were also observed by Zhou et al. in a porous-plug/jet burner ${ }^{17,18}$. Variations in preheat zone thickness with turbulence intensity and HAB are discussed in greater detail in section III.B.b below.

In contrast to the preheat zone, trends associated with the reaction zone thickness are more difficult to extract from Figure 8. This is because segments of both thick and relatively thin (i.e. $\delta_{\mathrm{RZ}, \mathrm{T}} \sim 2^{*} \delta_{\mathrm{RZ}, \mathrm{L}}$ ) reaction zones can be seen throughout the entire FOV in each of the four images. In fact the appearance of the observed reaction zones can best be described as resembling "chicken noodle soup." That is, relatively thin, "noodle-like" reaction zones are generally accompanied by thicker "chunky-chicken-like" reaction regions in any given instantaneous image. Take for example Figures 8C and 8D where blobby, distributed reaction regions are intermixed with relatively long and thin reaction zones. Furthermore, as will be seen in Figures $10-13$, even though $\operatorname{Re}_{\mathrm{T}}, \mathrm{Da}_{\mathrm{T}}$, and $\mathrm{Ka}_{\mathrm{T}}$ vary substantially, this "chicken noodle soup" reaction zone structure is consistent across all of the cases considered here. These observations suggest that it may not be appropriate to associate a single, pure flame structure to a particular set of operating conditions.

To more finely resolve flame structures and to obtain quantitative data from the instantaneous PLIF images, two zones of relatively high resolution $(40 \mu \mathrm{m} / \mathrm{pixel})$ were selected for each case. The initial field of view for these zones was $20 \times 20 \mathrm{~mm}^{2}$, but this was cropped to $13 \times 20 \mathrm{~mm}^{2}$ to exclude regions of low laser light intensity. The relative locations of these zones are depicted in Figure 9 below.

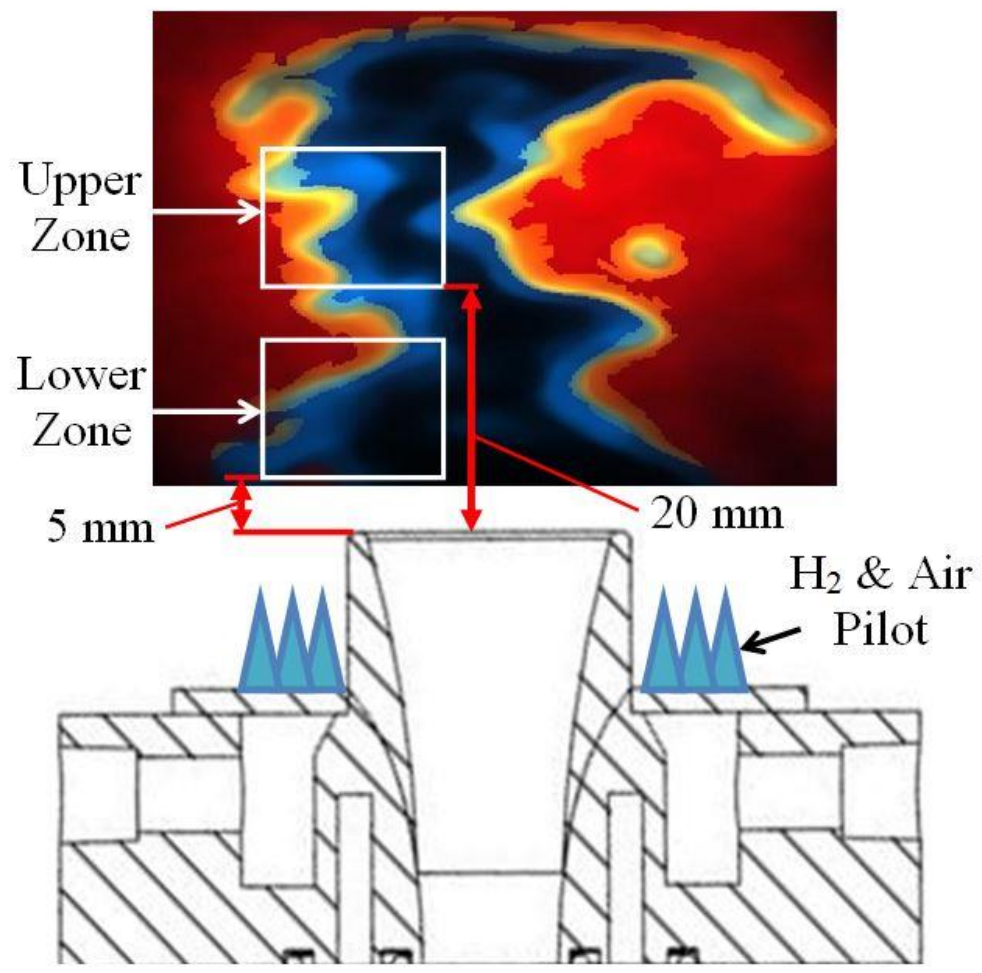

Figure 9. Diagram depicting the relative locations of the upper and lower zones. Note that the field of view for this image is $22 \times 36 \mathrm{~mm}^{2}$.

As Figure 9 shows, zone 1 and zone 2 span regions between $5 \mathrm{~mm}$ and $18 \mathrm{~mm}$ and between $20 \mathrm{~mm}$ and 33 $\mathrm{mm}$ above the burner, respectively. Sample images acquired from the lower zones of cases $1 \mathrm{~b}$ and $2 \mathrm{~b}$ and from the upper zones of cases 2a and 4a are displayed in Figures 10 - 13, respectively. Images from the other seven cases are excluded for the sake of brevity and because they exhibit similar traits as the images below. 


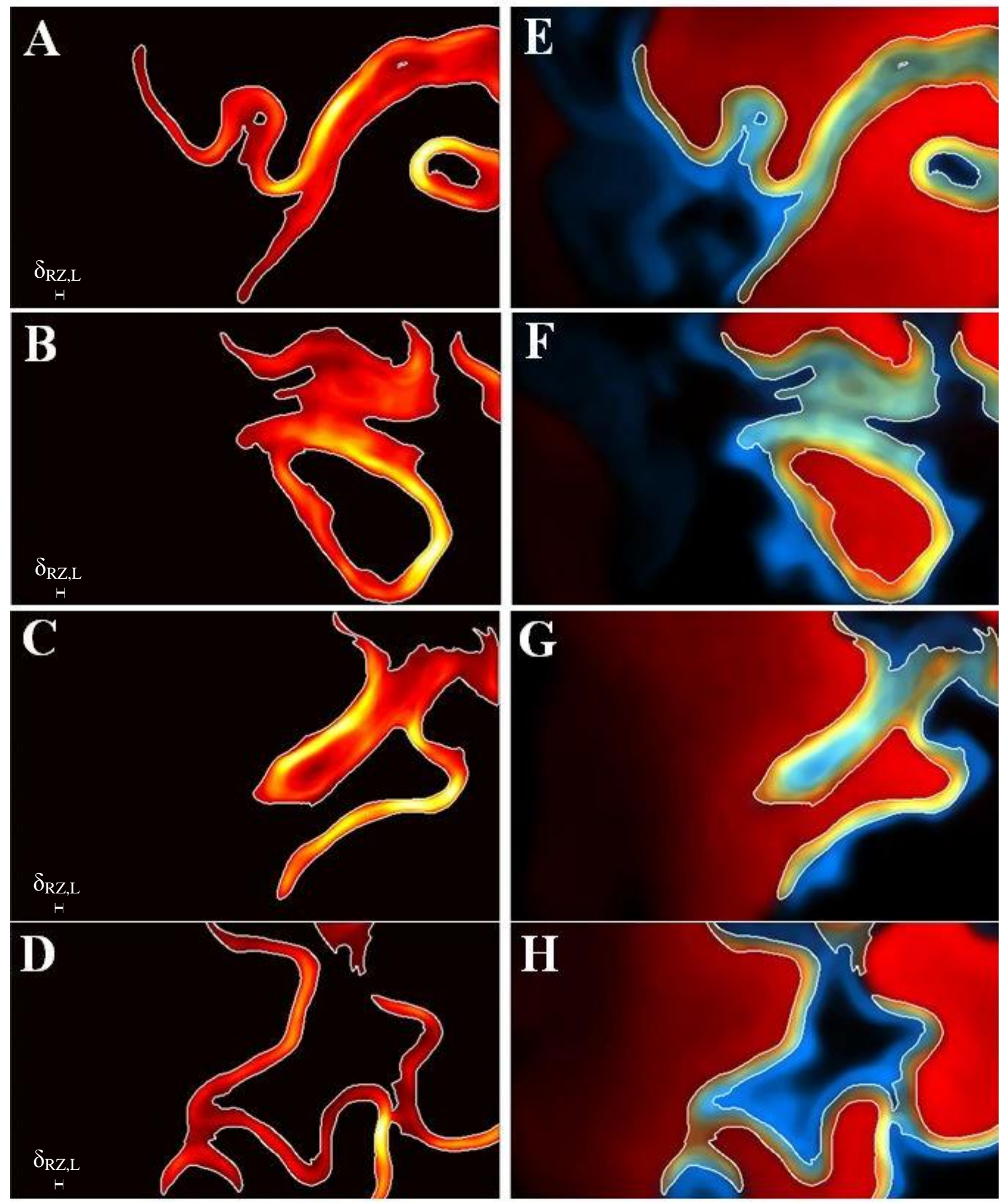

Figure 10. Representative images from the lower zone of case 1b. Post-processed, instantaneous images of the derived reaction zone are displayed in panels (A) - (D). Panels (E)-(F) display a compilation of all three signals, where blue indicates $\mathrm{CH}_{2} \mathrm{O}$ signal, red indicates $\mathrm{OH}$ signal, and yellow indicates the reaction zone. 


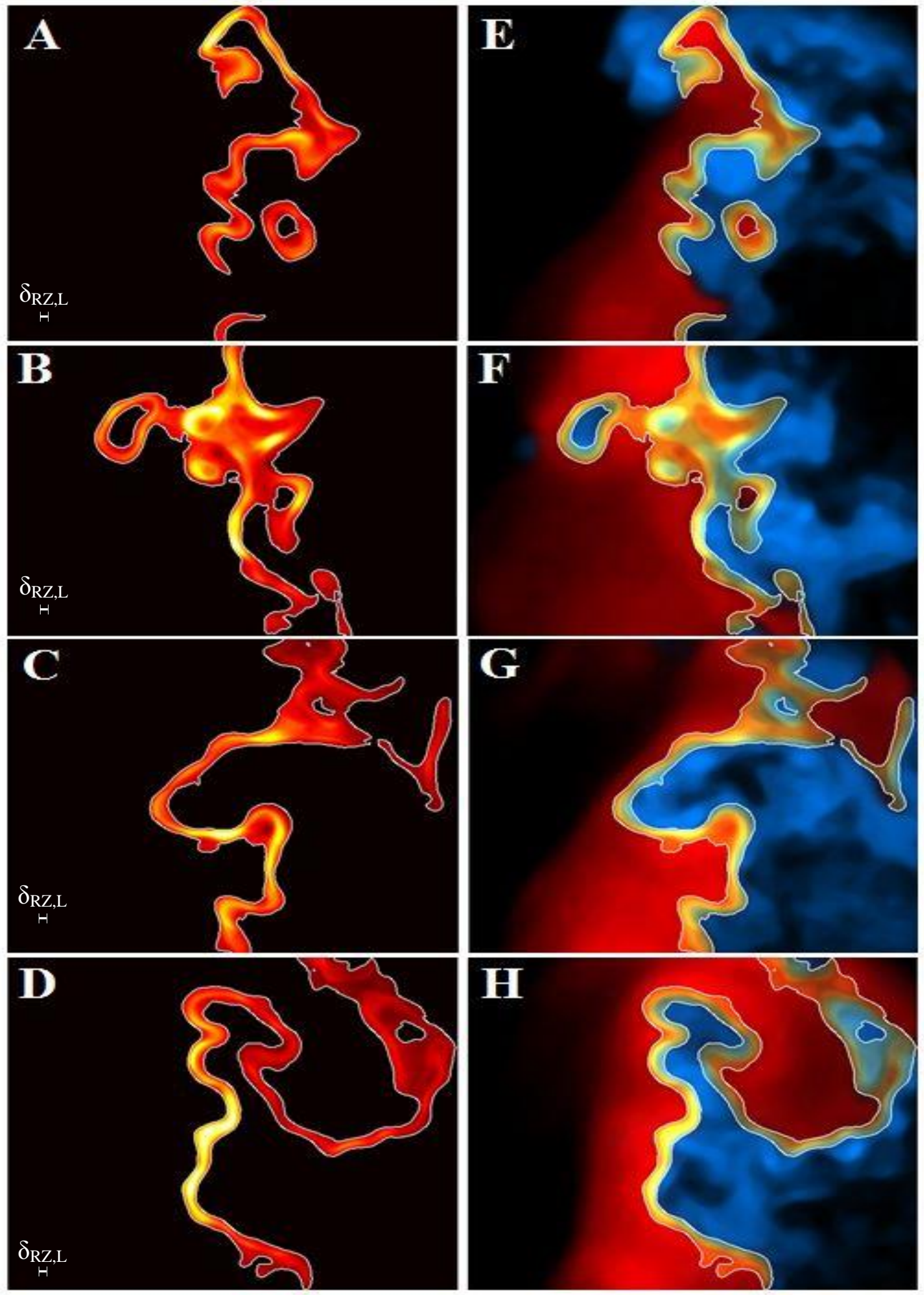

Figure 11. Representative images from the lower zone of case 2b. Post-processed, instantaneous images of the derived reaction zone are displayed in panels (A) - (D). Panels (E)-(F) display a compilation of all three signals, where blue indicates $\mathrm{CH}_{2} \mathrm{O}$ signal, red indicates $\mathrm{OH}$ signal, and yellow indicates the reaction zone. 

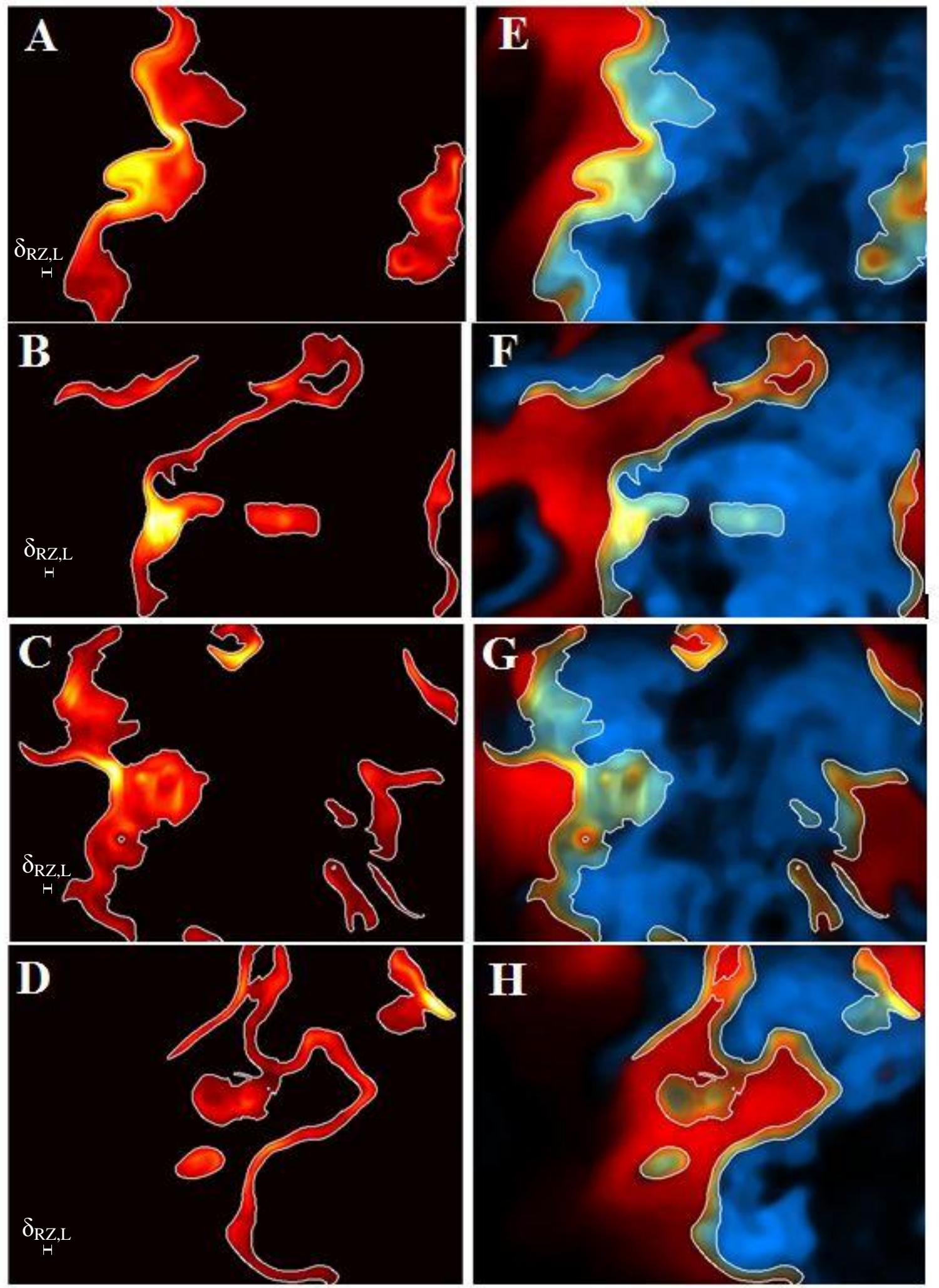

Figure 12. Representative images from the upper zone of case 2a. Post-processed, instantaneous images of the derived reaction zone are displayed in panels (A) - (D). Panels (E)-(F) display a compilation of all three signals, where blue indicates $\mathrm{CH}_{2} \mathrm{O}$ signal, red indicates $\mathrm{OH}$ signal, and yellow indicates the reaction zone. 

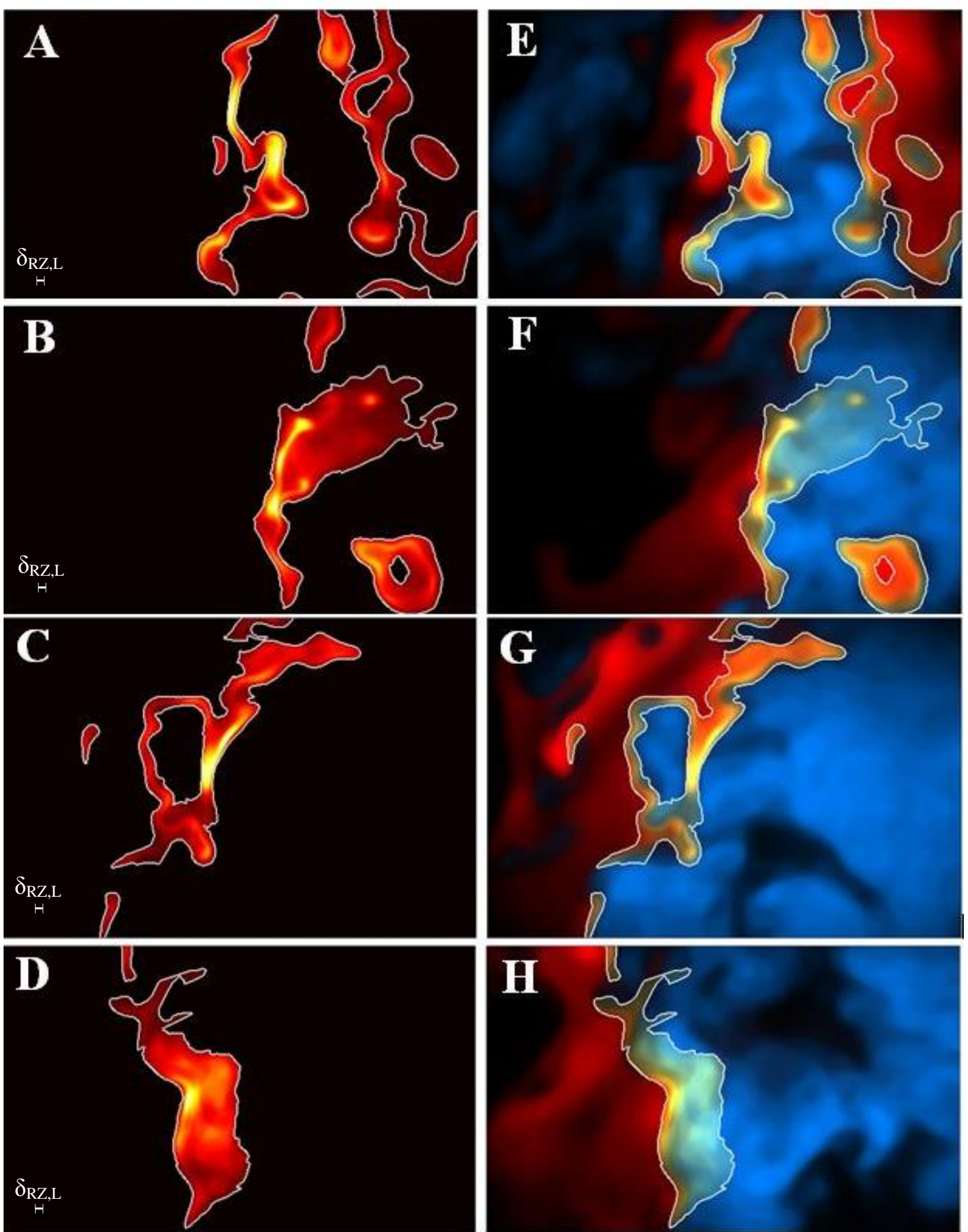

Figure 13. Representative image from the upper zone of case 4a. Post-processed, instantaneous images of the derived reaction zone are displayed in panels (A) - (D). Panels (E)-(F) display a compilation of all three signals, where blue indicates $\mathrm{CH}_{2} \mathrm{O}$ signal, red indicates $\mathrm{OH}$ signal, and yellow indicates the reaction zone. 
These higher resolution images emphasize the patterns seen in Figure 8. That is, the preheat zone thickness increases with increasing turbulence intensity while the reaction zone layers take on a variety of shapes. Specifically, while images taken from the lower zone of case 1b's flame (shown in Figures $10 \mathrm{E}-10 \mathrm{H}$ ) exhibit preheat zones that are only slightly larger than the reaction zones, images from the upper zone of case 4a (shown in Figures $13 \mathrm{E}-13 \mathrm{H}$ ) show preheat zones that completely fill the flame brush. This trend of increasing preheat zone thickness with increasing turbulence intensity is discussed further in section III.B.b below.

As alluded to above, unlike the preheat zones, trends associated with the reaction zones cannot be easily extracted from Figures $10-13$. Take for example case 1b, which was the least turbulent case considered and, based on its boundary conditions, is classified into the "thin reaction zone" regime (see Figure 1). Nevertheless, Figures $10 \mathrm{~B}$ and 10C clearly show that it is possible for this case's reaction zones to become thick and distributed. On the other hand, case $4 \mathrm{a}$ was the most turbulent case considered and, according to its measured boundary conditions, falls into the "distributed reaction zone" regime (see Figure 1). Yet, relatively thin reaction zone structures are observed in Figures 13A and 13C. Additionally, Figures 11 and 12 demonstrate that both thick and thin reaction regions exist within moderately turbulent flow fields. The fact that each case exhibits a soupy mixture of thin and distributed reaction zones leads to average reaction zone thicknesses that vary only slightly with dramatic changes in $\mathrm{Re}_{\mathrm{T}}, \mathrm{Da}_{\mathrm{T}}$, and $\mathrm{Ka}_{\mathrm{T}}$. Average reaction and preheat zone thicknesses are presented and discussed in the following section.

\section{b. Average thicknesses of preheat and reaction zones}

Average preheat and reaction zone thicknesses were determined for each of the $\mathrm{CH}_{2} \mathrm{O}$ PLIF images and the product of the $\mathrm{OH}$ and $\mathrm{CH}_{2} \mathrm{O}$ PLIF images, respectively. Over 250 PLIF image pairs of $\mathrm{OH}$ and $\mathrm{CH}_{2} \mathrm{O}$ were acquired for each case and the details of how average thicknesses were computed from these images are provided in section II.B above. The datum points in Figure 14 below represent an ensemble average of the preheat zone thicknesses over all images taken for each case.

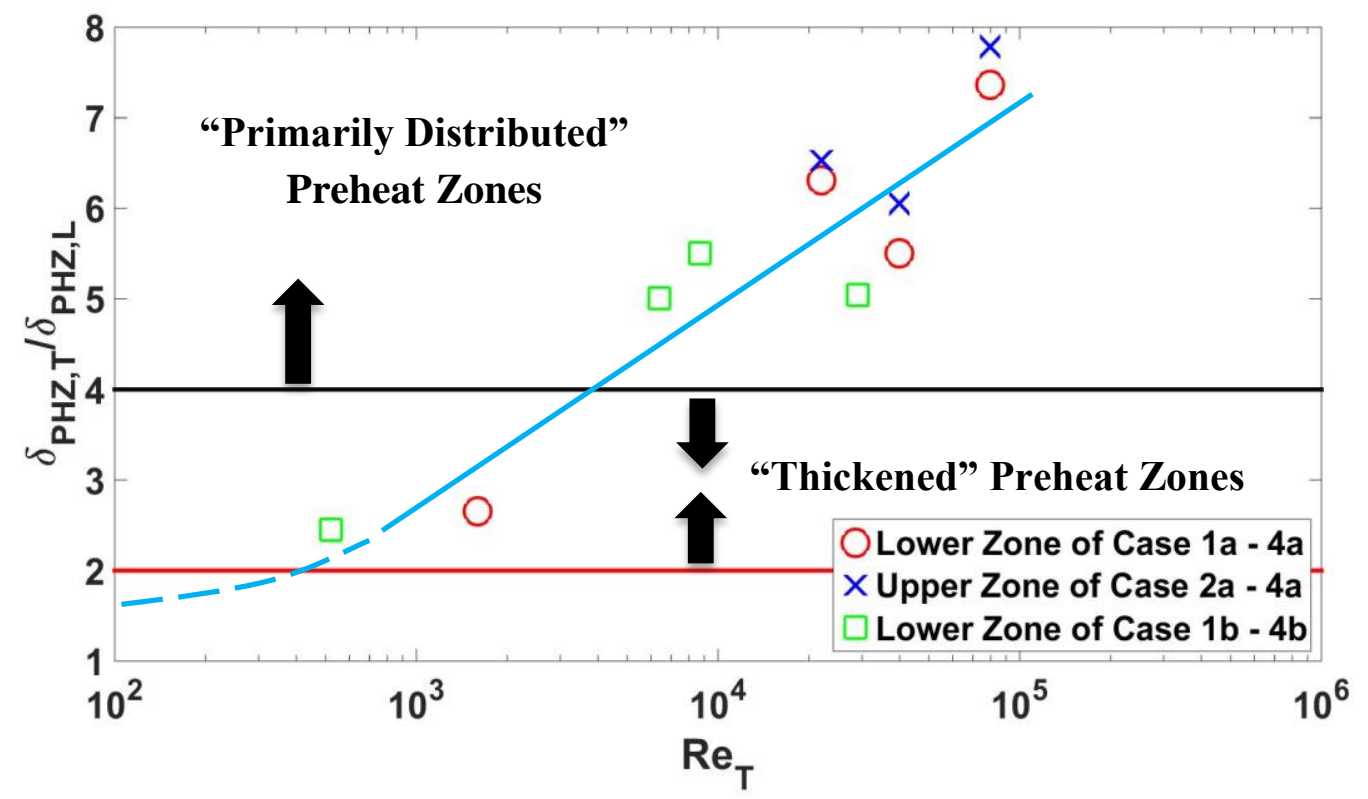

Figure 14. Average preheat zone thickness normalized by the un-stretched laminar preheat zone thickness as computed in Chemkin $(0.36 \mathrm{~mm})$ as a function of $\mathrm{Re}_{\mathrm{T}}$.

Figure 14 clearly shows that the preheat zone thickness increases with turbulence Reynolds number. However, the linear trend displayed by the results in Figure 14 suggest that the average preheat zone thickness is roughly a logarithmic function of $\mathrm{Re}_{\mathrm{T}}$, and hence possesses asymptotic qualities. That is, the average preheat zone thicknesses level off for $\mathrm{Re}_{\mathrm{T}}>6,400$. This asymptotic behavior makes sense because the area encapsulated by the flame brush is finite and for cases in which $\operatorname{Re}_{\mathrm{T}}>22,000$ the preheat zone is seen to fill the entire central region of the flame (see Figures $8 \mathrm{G}$ and $8 \mathrm{H}$ ). Furthermore, comparing the results from the lower and upper zones in Figure 14 , it is apparent that the average preheat zone thickness increases with height above burner. 
An increase in preheat zone thickness with height above burner can be associated with the fact that the flame brush typically widens downstream of the burner's exit, which is a consequence of the burner's diverging nozzle. Additionally, this trend could potentially be attributed to elevated turbulence levels at moderate heights above the burner, which were observed in similar jet burners ${ }^{17,48}$. However, in order to validate this hypothesis, characteristics of the Hi-Pilot flow field must be assessed at regions downstream of its exit.

The red horizontal line in Figure 14 marks the boundary between laminar and "thickened" preheat zones. The inequality defining this boundary is as follows:

$$
4>\frac{\delta_{\mathrm{PH}, \mathrm{T}}}{\delta_{\mathrm{PH}, \mathrm{L}}}>2
$$

Thus preheat zones that are more than two but less than four times as thick as those found in a laminar flame are identified as being "thickened." The reason for setting this boundary at twice the laminar thickness is because, as Zhao et al. ${ }^{17}$ mention, three-dimensional effects and severe flame wrinkling could cause layers to appear up to twice as thick as they would in a laminar flame. The boundary between "thickened" and "primarily distributed" preheat layers is marked by the black horizontal line in Figure 14. This boundary is defined by the inequality:

$$
\frac{\delta_{\mathrm{PH}, \mathrm{T}}}{\delta_{\mathrm{PH}, \mathrm{L}}}>4
$$

That is, the preheat zones associated with a particular case are deemed "primarily distributed" when the average preheat zone thickness exceeds four times the laminar value. This suggests that both the lower and upper zones of cases $2 a-4 a$ and the lower zones of cases $2 b-4 b$ all possess "primarily distributed" preheat zones, while the lower zones of cases 1a and 1b's preheat zones are "thickened." The definition of this boundary is supported by the PLIF images displayed in Figures $10-13$. From Figure 10 it is apparent that the preheat zones of case $1 \mathrm{~b}$ are relatively thin. Conversely, case 2b's preheat zones are substantially more distributed and are even seen to cover a significant portion of the FOV shown in panels $(\mathrm{G})$ and $(\mathrm{H})$ of Figure 11. Thus, Eq. (12) appears to mark the border between "thickened" and "primarily distributed" preheat zones reasonably well.

As in Figure 14, the data displayed in Figure 15 below is produced by averaging the reaction zone thicknesses over all images taken for each case.

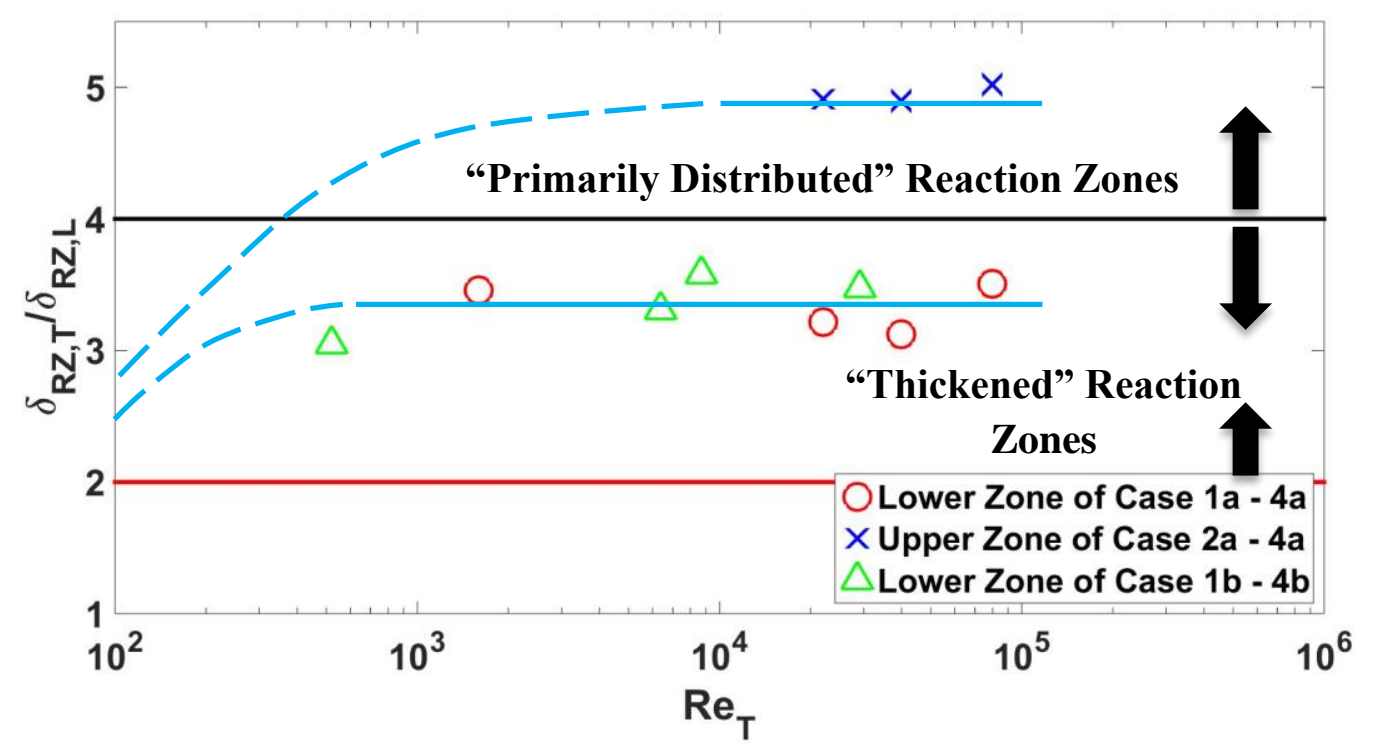

Figure 15. Average reaction zone thickness normalized by the laminar reaction zone thickness as computed in CHEMKIN $(0.18 \mathrm{~mm})$ for zones 1 and 2 as a function of turbulence Reynolds number. 
Unlike the average preheat zone thicknesses; Figure 15 implies that the average reaction zone thicknesses are relatively constant for a large range of turbulence intensities and integral length scales. This trend, or lack thereof, is consistent with the structural qualities of the reaction zones seen in Figures $10-13$. Namely, while regions of distributed reactions were observed in cases with both high and low turbulence levels; they typically were also accompanied by relatively thin reaction regions. Having both relatively thin and distributed reaction layers present in all of the cases is what leads to minor variation between the average reaction zone thicknesses.

Though the average reaction zone thicknesses vary only slightly within a particular zone, Figure 15 demonstrates that these values change considerably between zones. Specifically, the average reaction layer thicknesses in the upper zone of cases $2 \mathrm{a}-4 \mathrm{a}$ are nearly twice as thick as those in the lower zone. This trend is supported by the PLIF images presented above. That is, while both possess a range of reaction zone structures, those in the upper zone of case 2a (see Figure 12) have a higher tendency of being distributed than those in the lower zone of case $2 \mathrm{~b}$ (see Figure 11). As in the case of the preheat zone thickness this could be a result of increased turbulence levels at moderate heights above the burner. Yet, as mentioned above, properties of the flow field at regions downstream of the HPB's exit are necessary to justify this explanation. Such properties were unavailable for the current study.

Similar to the horizontal lines in Figure 14, the red and black horizontal lines in Figure 15 mark the boundaries between regimes of laminar and "thickened" and "thickened" and "primarily distributed" reaction zones, respectively. The red line is defined by the inequality:

$$
4>\frac{\delta_{\mathrm{RZ}, \mathrm{T}}}{\delta_{\mathrm{RZ}, \mathrm{L}}}>2
$$

while the black line is defined by the inequality:

$$
\frac{\delta_{\mathrm{RZ}, \mathrm{T}}}{\delta_{\mathrm{RZ}, \mathrm{L}}}>4
$$

That is, the reaction layers within in a particular zone of a specific case are designated as being "thickened" when that case's average reaction zone thickness exceeds two but is less than four times the laminar value. If the reaction layers exceed four times the laminar value, they're considered to be "primarily distributed." Thus, from Figure 15, it is apparent that lower zone reaction layers are identified as being "thickened" for all cases. Yet, on average, the reaction layers in the upper zone of cases $2 \mathrm{a}-4 \mathrm{a}$ are considered to be "primarily distributed." Even so, these cases still exhibit relatively thin reaction structures, though they appear less frequently than "locally distributed" regions. A parameter quantifying the percentage of "locally distributed" reactions was computed and is the focus of the next section.

\section{Percentage of locally distributed reaction zones}

As is apparent from Figures $10-15$, reaction zones can exhibit a wide range of topological features. Namely, a single reaction zone image can showcase both thickened flamelets as well as distributed reaction regions. In order to quantify the amount of locally distributed regions a parameter was defined and is given in Eq. (15) below:

$$
\text { locally distributed } \equiv\left\{\begin{array}{l}
\frac{\delta_{\mathrm{RZ}, \mathrm{T}}}{\delta_{\mathrm{RZ}, \mathrm{L}}}>4 \\
\frac{\text { Length }}{\delta_{\mathrm{RZ}, \mathrm{T}}}<4
\end{array}\right.
$$

The same skeleton used in determining the reaction zone thickness is also used to compute this parameter. At each point on the skeleton the distributed parameter was evaluated inside a 40 x 40 pixel neighborhood to determine if the flame was locally thick or locally distributed. Regions of locally distributed reactions are identified by the black skeleton lines in Figures 16A-16D, for cases 1a - 4a, respectively. 

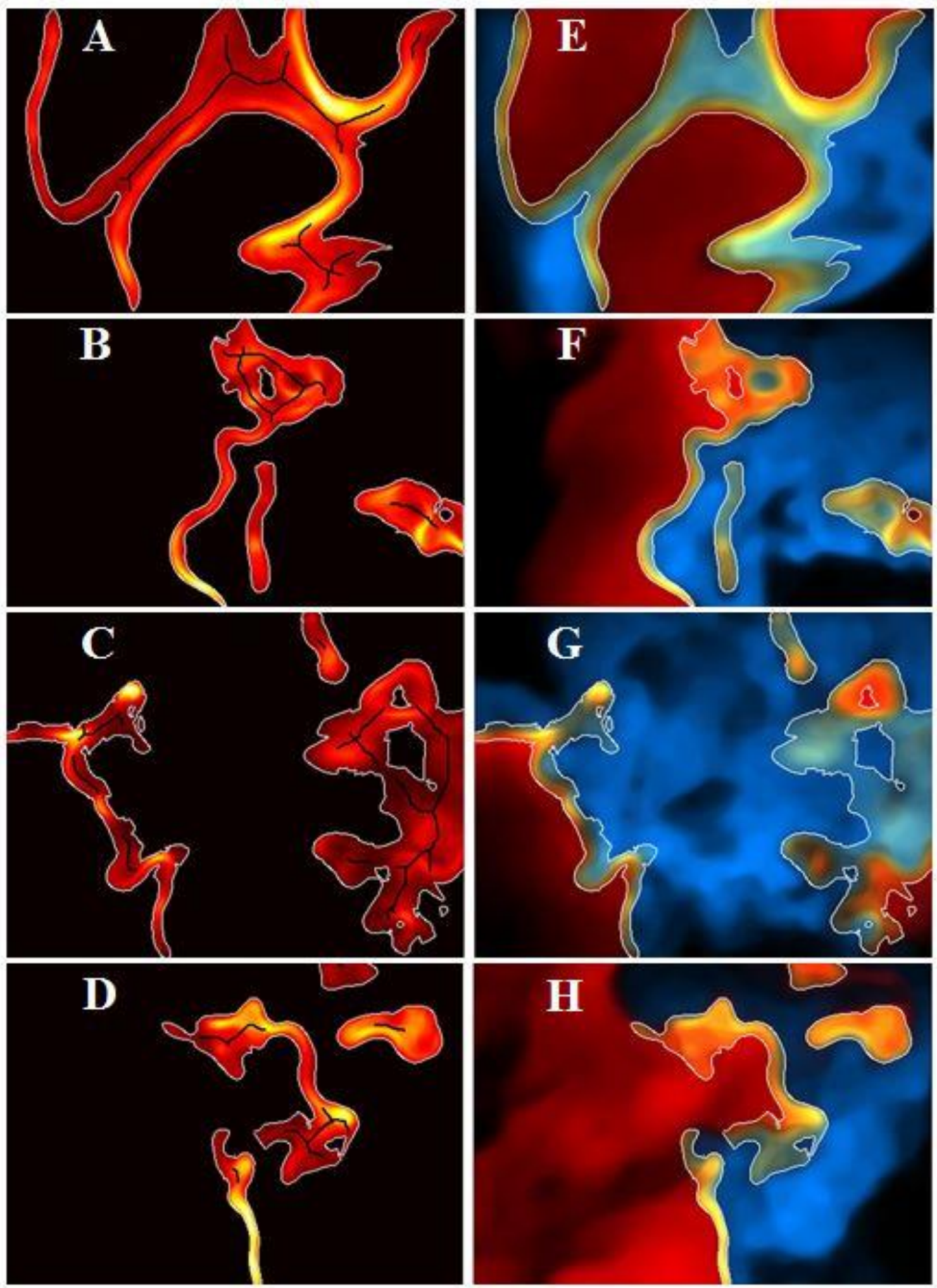

Figure 16. Examples of distributed reaction zone parameter marking. Black skeleton lines indicate the region is locally distributed. Panels (A) - (D) display reaction zones for cases 1a-4a. Panel (C) was taken from the upper zone; the rest were taken from the lower zone. Panels $(\mathrm{E})-(\mathrm{H})$ show all three signals for the associated cases in panels (A) - (D). Blue indicates $\mathrm{CH}_{2} \mathrm{O}$ signal, red indicates $\mathrm{OH}$ signal, and yellow signifies the reaction zone. 
Like Figures $10-13$, Figure 16 suggests that localized regions of both thickened and distributed reaction zones exist in nearly all of the cases considered here. To clearly show that this trend persists over a large range of turbulence levels, the average percentages of "locally distributed" reaction zones were computed and are plotted against $\operatorname{Re}_{\mathrm{T}}$ in Figure 17.

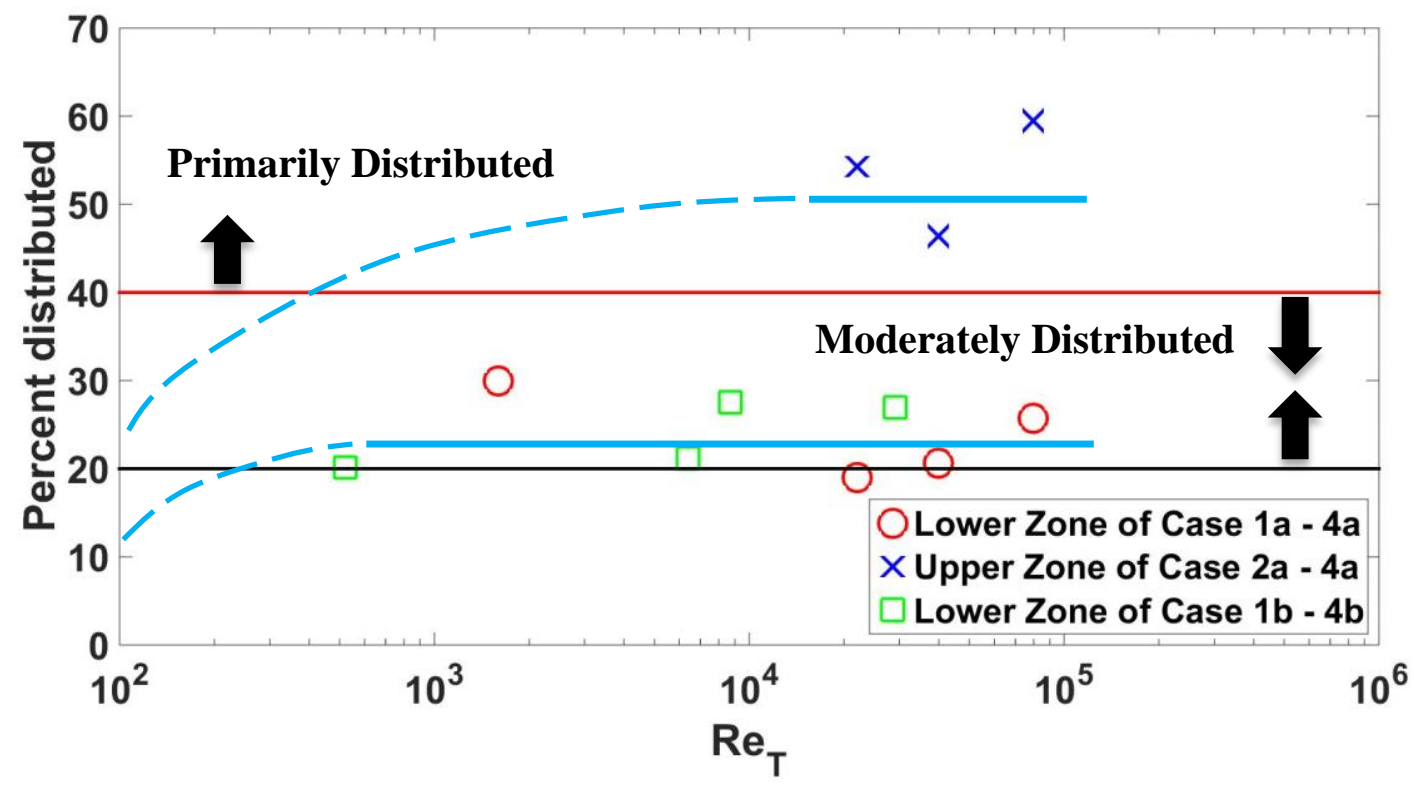

Figure 17. Percentage of locally distributed reaction regions as a function of turbulent Reynolds number.

On average, cases that fall between the black and red horizontal lines in Figure 17 are considered to possess "moderately distributed" reaction zones. A single reaction zone is deemed "moderately distributed" if more than $20 \%$ of that reaction zone is identified as being "locally distributed." Furthermore, if more than $40 \%$ of a reaction zone is "locally distributed," it is considered to be "primarily distributed." Hence, on average, the reaction zones lying above the red, horizontal line in Figure 17 are "primarily distributed."

The only "primarily distributed" reaction zones are those in the upper zone of cases $2 \mathrm{a}-4 \mathrm{a}$, which is consistent with the results displayed in Figure 15. Furthermore, much like the average reaction zone thicknesses, the percent of "locally distributed" reaction zones varies little over a large range of turbulence levels. The results of Figure 17 clearly indicate that localized regions of thickened and distributed reaction zones can exist within a particular flow field regardless of its positioning on the regime diagram. A discussion comparing the observed flame structures to those predicted by the regime diagram in Figure 1 is provided in the following section.

\section{Regime diagram inconsistencies}

In comparing the reaction zone structures observed here to those forecasted by the regime diagram presented in Figure 1, some distinctions are apparent. For example, cases 1a and $1 \mathrm{~b}$ are located at the lower edge of the "thin reaction zone" regime, where turbulent flow structures are able to penetrate the preheat zone, but not the reaction zone ${ }^{20}$. Thus, reaction zones within this regime are thought to remain thin. However, nearly $30 \%$ and $20 \%$ of the reaction zones in cases $1 \mathrm{a}$ and $1 \mathrm{~b}$, respectively, are identified as being "locally distributed." Hence, per the definitions given in section III.C above, both of these cases are considered to be "moderately distributed." Furthermore, as can be seen from Figure 14, the average reaction zone thicknesses of cases 1a and $1 \mathrm{~b}$ are three times the laminar value. This isn't surprising given that even the thinnest reaction layers for case $1 \mathrm{~b}$ are typically twice as thick as those in a laminar flame (see Figure 10).

Similarly sized reaction layers are also found in case 4a (see Figures 13A and 13C) even though its flow characteristics place it within the "distributed reaction" regime. Flames categorized into this regime are theorized as possessing reaction layers that are homogeneously spread throughout the entire domain of the turbulent flame 
brush $^{49}$. Though reaction layers in the upper zone of case 4a are "primarily distributed," relatively thin layers are still observed. What's more, is that reaction layers within the lower zone of case $4 \mathrm{a}$ are actually less distributed than those in case 1a. In fact, Figure 16D clearly illustrates that relatively thin reaction layers can exist within the highly turbulent flows of case $4 \mathrm{a}$. Based on these findings it appears that classical flame structure descriptions posited by a case's positioning on the regime diagram fail to capture the features observed in actual flames.

In addition to the discrepancies noted above, previous investigations ${ }^{48,50-52}$ have also noticed inconsistent correlations between observed flame structures and those predicted by a case's location on the regime diagram. For instance, though the least turbulent case of Dunn et al. ${ }^{48}$ was classified into the "distributed reaction" regime, temperature images identified this case's flame front as being relatively thin. On the other hand, the most turbulent case investigated by Allison et al. ${ }^{52}$, which was also categorized into the "distributed reaction" regime, possessed thinner thermal layers than flames at lower turbulence levels.

Dunn et al. ${ }^{48}$ do offer a tentative explanation as to why their seemingly thin flame is classified into the "distributed reaction" regime. They point out that the regime diagram in Figure 1 assumes that turbulence-flame interactions only occur in the direction normal to the flame front and in flow fields that are homogeneous and only moderately turbulent. Yet, the flow field generated by their burner, as well as the one utilized in this study, is severely turbulent (e.g. ' ' $/ \mathrm{S}_{\mathrm{L}}>180$ ) and is most likely inhomogeneous. Other possible explanations for discrepancies between observed flame structures and the features projected by the regime diagram are as follows:

1. Classical theory posits that reaction zones become distributed or shredded when enough energy can be stored within turbulent flow structures that are able to penetrate a laminar flame's reaction zone $\mathrm{e}^{20}$. However, as shown above, the preheat zone becomes distributed for $\operatorname{Re}_{\mathrm{T}}>6,400$. Therefore, prior to reaching the reaction zone, turbulent structures must first pass through the preheat zone, which consists of a relative large region of elevated temperatures. These elevated temperatures cause the local kinematic viscosity to increases, which enhances dissipation and thus draws energy away from the smallest turbulent structures. Hence, though turbulent structures of sufficient size and energy may exist at the burner's exit, it is possible that they are destroyed by the time they reach the reaction zone.

2. As Peters ${ }^{20}$ suggests, the intermittent behavior of turbulent flows when $\mathrm{Re}_{\mathrm{T}}$ is sufficiently large $\mathrm{S}^{53}$ could permit the flame to take on a variety of configurations within a single flow field.

3. Turbulence intensities produced by the HPB are generally varied by changing the overall mass flow rate of the reactants. This implies that the most turbulent cases also possess the greatest flow velocities. Such high velocities likely reduce the interaction time between turbulent flow structures and the flame front. Without a sufficiently long residence time, it is possible for even the most violent of turbulent structures to pass over the flame front without significantly broadening or extinguishing it.

4. A flame's stabilization mechanism appears to affect its structural features. At sufficiently large $\mathrm{Ka}_{\mathrm{T}}$, combustion will exhibit either broken or distributed reaction zones ${ }^{18}$. Broken reaction zones (i.e. the presence of localized quenching) can result from intense turbulence and the entrainment of cool room air to the reaction surface. To prevent such entrainment, Zhao et al. ${ }^{18}$ used a coflow to surround their flame with hot products, which allowed reaction zones to become distributed. The present experiment does not provide a hot coflow to support combustion at large downstream positions (such as the upper zone in this study), and therefore significant room-air entrainment occurs at these locations. Such processes modify the observed combustion mode, and are not accounted for in the construction of the current regime diagrams.

However, further investigations involving the simultaneous acquisition of both flow field and flame structure data are required to validate these premises. Such investigations are planned for the future. Nevertheless, the current investigation strongly suggests that the regime diagram requires alterations in order to accurately describe structural features of real turbulent flames. A starting point for such alterations are provided in section III.E below, where the cases presented in this document are categorized into their appropriate regimes of combustion. 


\section{E. Regimes associated with the measurements to date}

As mentioned above, the data presented here as well as in other studies ${ }^{48,52-54}$, suggest that modifications should be made to the regime diagram. The present data set is too limited to provide a comprehensive re-mapping of the regime diagram; however, the cases studied here have been associated with a particular regime based on their structural features.

Specifically, a case is classified as being "primarily distributed" if its mean thickness exceeds four times the laminar value. Additionally, if at a specific point on a single reaction zone the thickness is locally four times thicker than the laminar value and its length to thickness ratio is less than four, it is identified as being "locally distributed" at that point. A reaction zone is defined to be "moderately distributed" when $20 \%$ but less than $40 \%$ of the reaction surface consists of "locally distributed" reaction zones. If more than $40 \%$ of a reaction surface is "locally distributed" it is also identified as being "primarily distributed."

The categorization of each case into its appropriate regime was based on the aforementioned definitions and the data shown in the figures above. A summary of this categorization is provided in Table 2 below.

\begin{tabular}{cccc}
\hline Case & Interrogation region & Preheat zone & Reaction zone \\
\hline 1a & lower zone & "thickened" preheat zone & "thickened" reaction layers \\
2a & lower zone & "primarily distributed" preheat zone & "thickened," "moderately distributed" reactions \\
& upper zone & "primarily distributed" preheat zone & "primarily distributed" reaction layers \\
3a & lower zone & "primarily distributed" preheat zone & "thickened," "moderately distributed" reactions \\
& upper zone & "primarily distributed" preheat zone & "primarily distributed" reaction layers \\
4a & lower zone & "primarily distributed" preheat zone & "thickened," "moderately distributed" reactions \\
& upper zone & "primarily distributed" preheat zone & "primarily distributed" reaction layers \\
1b & lower zone & "thickened" preheat zone & "thickened" reaction layers \\
2b & lower zone & "primarily distributed" preheat zone & "thickened," "moderately distributed" reactions \\
3b & lower zone & "primarily distributed" preheat zone & "thickened," "moderately distributed" reactions \\
4b & lower zone & "primarily distributed" preheat zone & "thickened," "moderately distributed" reactions \\
\hline
\end{tabular}

Table 2. Classification of the four cases studied in this paper.

\section{Conclusions}

1. Eight different non-reacting flow fields issuing from the HPB were characterized using laser Doppler Velocimetry (LDV). The turbulence Reynolds number of these four cases spanned from 520 to 80,000, the turbulence intensity (i.e. $\mathrm{u}^{\prime} / \mathrm{S}_{\mathrm{L}}$ ) ranged from 5 to 184, and the integral length scale varying between $6 \mathrm{~mm}$ and $29 \mathrm{~mm}$.

2. Preheat zone thicknesses, based on $\mathrm{CH}_{2} \mathrm{O}$ PLIF signals, were found to exceed seven times the laminar value. Eight of the eleven cases considered possessed average preheat zone thicknesses above four times the laminar thickness, hence these cases were identified as having "primarily distributed" preheat zones.

3. As the turbulence Reynolds number increases beyond 6,400, preheat zone thickness exhibit an asymptotic behavior. This is believed to occur because there is a finite amount of area within the conical region of reactants inside the flame brush, and for $\mathrm{Re}_{\mathrm{T}}>22,000$ the preheat zone becomes so large that it fills the entire central region of the flame. Therefore, the preheat zone cannot grow any larger for this geometry.

4. Reaction zones were identified by taking the pixel-by-pixel product of the $\mathrm{OH}$ and $\mathrm{CH}_{2} \mathrm{O}$ PLIF images. For a particular investigation region, no significant variation in average reaction zone thicknesses was observed across the cases. However, the average reaction zone thickness did vary substantially between the two regions. 
5. All of the reaction layers within the lower zone were "thickened" and, except in one case, were considered to be "moderately distributed," while all of the reaction layers within the upper zone were deemed "primarily distributed."

6. Despite being categorized as "moderately" or "primarily distributed," each case's reaction zones exhibited regions of both relatively thin and distributed reactions. This fact is what leads to little variation between average reaction zone thicknesses.

7. In general, the observed reaction zone structures in a particular case do not correspond to those predicted by the Borghi Diagram. Thus, it is likely that the regime diagram will have to be altered if it is to accurately describe structural features of real turbulent flames.

8. The current data set is too limited to provide a comprehensive re-mapping of the regime diagram. However, the cases considered in this study were classified into appropriate regimes of combustion.

\section{Acknowledgements}

Support for this research was provided by AFOSR Grant FA9550-12-1- 0101 that was monitored by Dr. Chiping Li.

\section{References}

${ }^{1}$ I.G. Shepherd, R. K. Cheng, Combust. Flame 127 (2001) 2066-2075.

${ }^{2}$ A. Buschmann, F. Dinkelacker, T. Schafer, M. Schafer, J. Wolfrum, J.. Proc Combust. Inst. 26 (1996) 437-445.

${ }^{3}$ A. Soika, F. Dinkelacker, A. Leipertz, Proc. Combust. Inst . 27 (1998) 785-792.

${ }^{4}$ Y.-C. Chen, R. W. Bilger, Combust. Flame 131(2002) 400-435.

${ }^{5}$ J. F. Driscoll, Prog. Energy \& Combust. Sci. 34 (2008) 91-134.

${ }^{6}$ A.M.Steinberg, J.F. Driscoll, Combust. Flame 156 (2009) 2285-2306.

${ }^{7}$ A. M. Steinberg, J. F. Driscoll, Expts. in Fluids 47 (2009) 527-547.

${ }^{8}$ J. B. Bell, M.S. Day, J. F. Grcar, M.J. Lijewski, J. F. Driscoll, S. Filatyev, Proc. Combust. Inst. 31 (2007) 12991307.

${ }^{9}$ H. Kobayashi, T. Kawahata, K. Seyama, T. Fujimari, J.S. Kim, Proc. Combust. Inst. 29 (2002) 1793-1800.

${ }^{10}$ R. Sankaran, E.R. Hawkes, J.H. Chen, JH., Proc, Combust, Inst, 31(2006)1291-1298.

${ }^{11}$ F.T.C. Yuen, O. Gulder, Proc. Combust. Inst. 34 (2013) 1393-1400.

${ }^{12}$ Mansour, M.S. Chen, Y.-C., Peters, N., Proc. Combust. Inst. 24 (1992) 461-468.

${ }^{13}$ Chen, Y.-C., Peters, N., Schneemann, G.A., Wruck, N., Renz, U., and Mansour, M.S. Combust. Flame 107 (1996) 223-244.

${ }^{14}$ Chen, Y.-C., Mansour, M.S. Appl. Phys. B64 (1997) 599-609.

${ }^{15}$ M.J. Dunn, A. R. Masri, R. W. Bilger, R.S. Barlow, G.S. Wang, Proc. Combust. Inst. 32 (2009) 1779-1786.

${ }^{16}$ M.J. Dunn, A. R. Masri, R. W. Bilger, R S. Barlow, Flow Turbulence Combust. 85 (2010) 621-648.

${ }^{17}$ B. Zhou, C. Brackmann, Z. Li, M. Alden, X. Bai, Combust. Inst. 35 (2015) $1409-1416$.

${ }^{18}$ B. Zhou, C. Brackmann, Q. Li, Z. Wang, P. Petersson, Z. Li, M. Alden, X. Bai, Combustion \& Flame, 162 (2015) 2937-2953.

${ }^{19}$ F. A. Williams, Combust. Flame 26 (1976) 269-276.

${ }^{20}$ N. Peters, Turbulent Combustion, Cambridge U. Press, Cambridge UK, 2000.

${ }^{21}$ A. J. Aspden, M. S. Day, J. B. Bell, J. Fluid Mech. 680 (2011) 287-320.

${ }^{22}$ R. Borghi, Prog. Energy Combust. Sci. 14 (4) (1988) 245-292.

${ }^{23}$ A. Marshall, P. Venkateswaran, D. Noble, J. Seitzman, T. Lieuwen, Expt. Fluids 51 (2011) 611-620.

${ }^{24}$ B. Videto, D. Santavicca, Combust. Sci. Technol. 76 (1991) 159-164.

${ }^{25}$ T. Hedman, K. Cho, A. Satija, L. Groven, R. Lucht, S. Son, Experimental observation of the flame structure of a bimodal ammonium perchlorate composite propellant using 5 kHz PLIF, Combustion and Flame 159 (2012) 427437 
${ }^{26}$ M. Richter, R. Collin, J. Nygren, M. Alden, L. Hildingsson, B. Johansson, Studies of the Combustion Process with Simultaneous Formaldehyde and OH PLIF in a Direct-Injected HCCI Engine, JSME International Journal, Series B, Vol 48, No. 4, 2005.

${ }^{27}$ P.H. Paul, H.N. Najm, Proc. Combust. Inst. 27 (1998) 43-50.

${ }^{28}$ S. Böckle, J. Kazenwadel, T. Kunzelmann, D-I. Shin, C. Schulz, J. Wolfrum. Proc. Combust. Inst. 28 (2000) 279286

${ }^{29}$ M. Röder, T. Dreier, C. Schulz, Applied Physics B 107 (2012) 611-617.

${ }^{30}$ M. Röder, T. Dreier, C. Schulz, Proc. Combust. Inst. 34 (2013) 3549-3556.

${ }^{31}$ B.O. Ayoola, R. Balachandran, J.H. Frank, E. Mastorakos, C.F. Kaminski, Combust. Flame 144 (2006) 1-16.

${ }^{32}$ A. Fayoux, K. Zahringer, O. Gicquel,.C. Rolond, Proc. Combust. Inst. 30 (2005) 251-257.

${ }^{33}$ H.N. Najm, P.H. Paul, C.J. Mueller, P.S. Wyckoff, Combust. Flame 113 (1998) 312-332.

${ }^{34}$ C.M. Vagelopoulos, J.H. Frank, Proc. Combust. Inst. 30 (2004) 241-249.

${ }^{35}$ R. Balachandran, B.O. Ayoola, C.F. Kaminski, A.P. Dowling, E. Mastorakos, Combust. Flame 143 (2005) 37-55.

${ }^{36}$ J. Kariuki, A. Dowlut, R. Yuan, R. Balachandran, Proc. Combust. Inst. 35 (2015) 1443-1450.

${ }^{37}$ R. Yuan, J. Kariuki, A. Dowlut, R. Balachandran, E. Mastorakos. Proc. Combust. Inst. 35 (2015) 1649-1656.

${ }^{38}$ H.N. Najm, O.M. Knio, P.H. Paul, P.S. Wyckoff, Combust. Sci. Tech. 140 (1998) 369-403.

${ }^{39}$ Wabel, T.M., Skiba, A.W., Temme, J.E., Driscoll, J.F., "Highly Turbulent Premixed Flame Structure - Integral Length Scale Effects", $9^{\text {th }}$ U. S. National Combustion Meeting, Cincinnati, Ohio, May 2015.

${ }^{40}$ Temme, J.E., Wabel, T.M., Skiba, A.W., Driscoll, J.F., 52nd Annual Aerospace Sciences Meeting, (2015) Kissimmee FL. ISBN-13:9781624102561

${ }^{41}$ Z. Li, B. Li, Z. Sun, X. Bai, M. Alden, Combustion and Flame 157 (2010) 1087-1096.

${ }^{42}$ Sumengen, B., "A Matlab toolbox implementing Level Set Methods," Vision Research Lab at UC Santa Barbara, California, October 2005. [http://barissumengen.com/level_set_methods/. Accessed 3/15/14.].

${ }^{43}$ Osher, S., Fedkiw, R., Level Set Methods and Dynamic Implicit Surfaces, Springer, New York, 2003.

${ }^{44}$ Mayo, W.T. Jr., A discussion of limitations and extensions of power spectrum estimation with burst-counter LDV systems. International workshop on laser velocimetry, West Lafayette, Indiana, Purdue University, pp 90-101, 1974.

${ }^{45}$ Tummers, M.J., Passchier, D.M. Spectral estimation using a variable window and the slotting technique with local normalization. Meas. Sci. Technol. 7:1541-1546, 1996.

${ }^{46}$ Wu, H., Patterson, G.K, Chemical Engineering Science, Vol. 44, No. 10, pp. 2207-2221, 1989.

${ }^{47}$ Kresta, S., Wood, P., Chemical Engineering Science, Vol. 48, No. 10, pp. 1761-1774, 1993.

${ }^{48}$ M.J. Dunn, A. R. Masri, R. W. Bilger, Combust. Flame 151 (2007) 46-60.

${ }^{49}$ Williams, F. A. 1985a Combustion Theory. Addison-Wesley.

${ }^{50}$ Chen, Y.-C. and Bilger, R. W., "Simultaneous 2-D Imaging Measurements of Reaction Progress Variable and OH Radical Concentration in Turbulent Premixed Flames: Instantaneous Flame-Front Structure," Combust. Sci. and Technol. 167, 2001, p.187-222.

${ }^{51}$ Y.-C. Chen, R. W. Bilger, Combust. Flame 138 (2004) 155-174.

${ }^{52}$ Allison, P.M., Shen, H., McManus, T.A., Sutton, J.A., 52nd Annual Aerospace Sciences Meeting, (2015) Kissimmee FL.

${ }^{53}$ Monin, A.S., Yaglom, A.M. (1975) Statistical Fluid Mechanics: Mechanics of Turbulence MIT Press, Cambridge, MA. 